\title{
REVIEW
}

\section{Imaging spectrum of periosteal lesions - Pictorial essay}

\author{
Subbarao Kakarla ${ }^{1,2, *}$
}

${ }^{1}$ KIMS Foundation and Research Centre, Minister Road, Secunderabad - 500003, Telangana, India

${ }^{2}$ Kakarla Subba Rao Radiological and Imaging Educational Sciences Trust (KREST), ShaikpetNala, Hyderabad - 500008, Telangana, India

\begin{abstract}
Periosteum is a multipotential membrane giving rise to variety of reactions when mineralized. Any stimulus mechanical, physiological, biological and pathological stimulus can produce periosteal reaction and is best seen on conventional films. However, in order to detect early periosteal reaction, Ultrasonography is the mode of choice of investigation. There is a spectrum of imaging findings but no one really is specific. The number of etiological factors as well as the number of imaging features are listed and described. The message is that periosteal reaction is a radiological sign and not a disease, although is encountered in many focal, multifocal and systemic disorders.
\end{abstract}

Keywords: Periosteum; infections; trauma; neoplastic; malignancies; systemic causes

*Corresponding author: Prof. Kakarla Subbarao, MS, D.Sc. (HON), FRCR, FACR, FICP, FSASMA, FCCP, FICR, FCGP, Chairman KREST, 8-1-300/2, ShaikpetNala, Hyderabad, 500008, Telangana, India. Email: subbaraokakarla25@gmail.com.

Received 15 April 2019; Revised 1 June 2020; Accepted 10 June 2020; Published 19 June 2020

Citation: Kakarla S. Imaging spectrum of periosteal lesions Pictorial essay. J Med Sci Res. 2020; 8(3):121-138. DOI: http:// dx.doi.org/10.17727/JMSR.2020/8-17

Copyright: (c) 2020 Kakarla S. Published by KIMS Foundation and Research Center. This is an open-access article distributed under the terms of the Creative Commons Attribution License, which permits unrestricted use, distribution, and reproduction in any medium, provided the original author and source are credited.

\section{Introduction}

The periosteum is a multi potential membrane and the cells give rise to a variety of reactions to various stimuli and is said to be a magic sleeve for the bone. Like the skin it swells, cracks and proliferates reacting to stimuli such as injury, inflammation, infection, metabolic disorders, toxic substances, primary and secondary neoplasms. Periosteal vessels arise from the capillary-rich periosteum and supply outer 15 to $20 \%$ of cortex normally. They are capable of supplying a much greater proportion of the cortex in the event of injury through the medullary blood supply [1] Besides reacting to stimuli, benign and malignant periosteal neoplasms also produce specific type of periosteal reactions. Periosteum envelops the cortex of diaphysis and metaphysis of long bones. It consists of an outer fibrous layer and in inner cellular/ cambium layer. In adults, it is mainly fibrous layer which is thin and quiescent. In children, it consists of two distinct layers which are thick and active. 
Periosteal reaction is rapid and more aggressive in growing children. Also, the periosteum is loosely attached as Sharpey's fibres are less numerous and shorter in children as compared with adults.

\section{Pathophysiology}

The cambium layer consists of various cells including fibrous, cartilaginous, osseous, ground cells and blood cells. The biological activity depends upon the patient's age and metabolic rate. It also depends upon the maturation of the lesion. The periosteal lesions arising from the deep cambium layer are firmly attached to the cortex. The subperiosteal lesions separating periosteum from outer surface of cortex are mostly post traumatic, post inflammatory, post inflective and post malignant reparative processes. The paraosteal lesions originate from the outer parafibrous layer and no mineralized periosteal reaction is noted.

\section{Periosteal reactions-Periostitis, periosteitis, periosteopathy}

They may be acute or chronic. Mineralization of periosteal reaction is essential for identification on a radiograph.

The acute periosteal reaction is often unilaminar, unilaminar-interrupted and sharply spiculated. The chronic periosteal reaction is often multilaminar, interrupted multilaminar, spiculated, compact, shaggy, fussy or in the form of Codman's triangle $[2,3]$. A combination of these are present in some instances. Etiological factors of periosteal reaction are listed in Table 1.

Table 1: Etiological factors of periosteal reaction.

\begin{tabular}{ll|}
\hline - & Physiological \\
- & Trauma- Healing fractures - Stress and insufficiency \\
- & Idiopathic \\
- & Infection \\
- & Hypertrophic osteoarthropathy - Primary, Secondary \\
- & Nutritional \\
- & Metabolic \& Endocrinal \\
- & Vasic \\
- & Neoplastic- Benign \& Malignant \\
- & Malignant- Primary \& Secondary \\
- & Miscellaneous - e.g., inflammatory bowel disease, \\
& cyanotic heart disease
\end{tabular}

\section{Imaging methods}

- Conventional radiology

- Ultrasonography

- $\quad$ CT

- $\quad$ PET CT

- $\quad$ MRI

- Nuclide scan

\section{Morphological classification of periosteal reactions}

More specific classification of periosteal reactions can be made to narrow the differential diagnosis. Types of periosteal reaction are listed in Table 2 . However, one cannot arrive at a diagnosis depending upon the morphological type of periosteal reactions. Different types of periosteal reactions may be noted in one entity. On the other hand, one type of periosteal reaction may be common in several diseases.

Table 2: Morphological types of periosteal reaction.

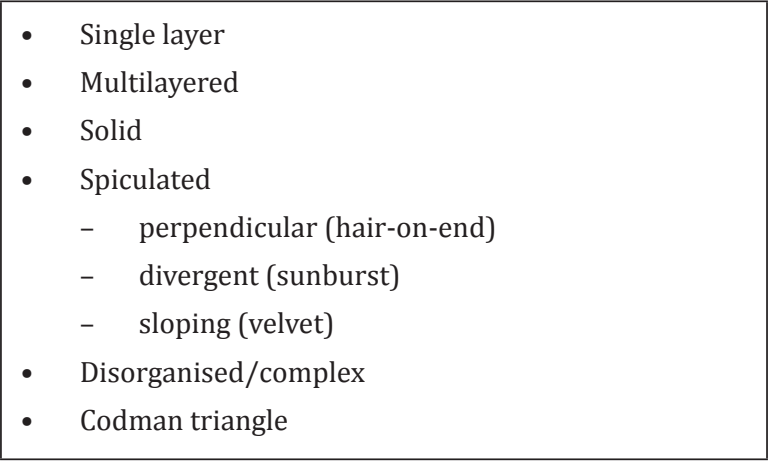

Larsen ME has modified the type of periosteal reactions and they are listed in Table 3.

Table 3: Types of periosteal reaction - Modified from Larson ME [5].

- $\quad$ Nonaggressive

$>$ Thin - linear

$>$ Solid-compact

$>$ Thick irregular - linear

$>$ Septated - mosaic

- Aggressive

- Multilaminar(onionskin)

$>$ Spiculated

$>$ Perpendicular/hair-on-end

- Sunburst - radiating

- Disorganized - mixed

- Codman triangle 
Conventional Radiology is the investigation of choice. It helps most of the time in guiding and leading to the correct diagnosis. Ultrasonography is more sensitive and detects periosteal reaction earlier than plain radiography. The other imaging methods help to confirm the diagnosis. Nuclear scan is non-specific but detects the activity of the lesion.

Periosteal reaction may be focal, multifocal or generalized. Bilateral symmetrical periosteal reaction often indicates a systemic disorder.

\section{Physiological}

In some infants, physiological periosteal reaction is noted along the lateral margins of femoral shafts as an incidental finding (Figure 1). As the child grows the periosteum blends with the cortex. Periosteal reaction along the medial margin should be considered as pathological [2].

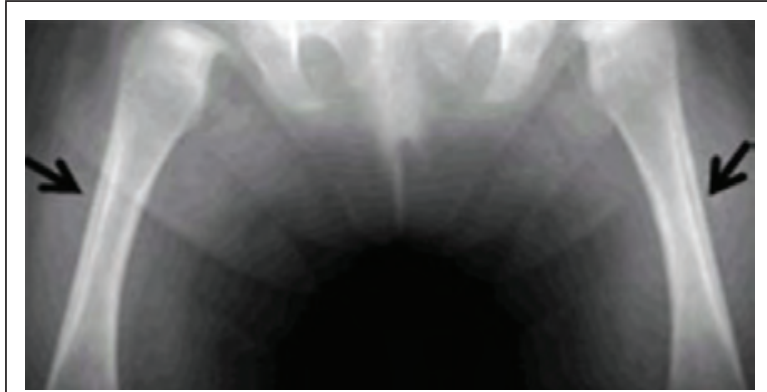

Figure 1: Physiological periosteal reaction in a baby of 4 months age.

\section{Pseudo periosteal reaction}

The line between the cortex and endosteum in long bones sometimes simulates periosteal reaction. It is encountered along the long bones e.g., lower end of humerus and mid shaft of femur (Figure 2a). Pseudo periosteal reaction is also noted in the postero medial aspect of the tibia $[3,4]$.

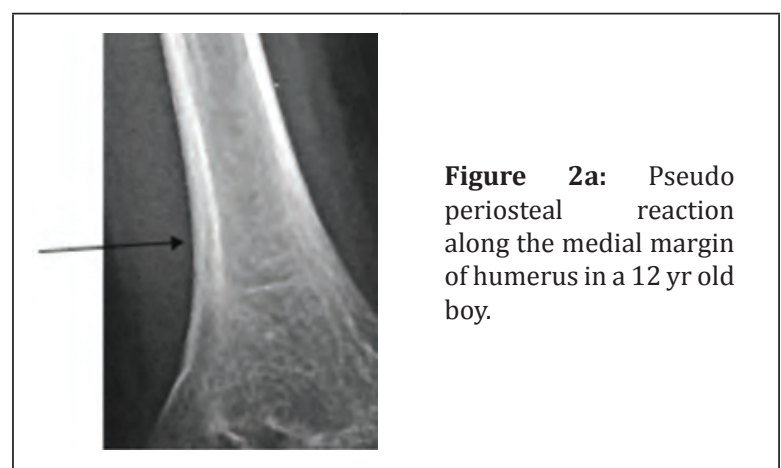

Pseudoperiostitis may also be noted in skeletal fluorosis due to ossification at the attachment of the muscles and tendons. Dystrophic calcification at the musculotendinous insertions may simulate periostitis (Figure $2 \mathrm{~b}$ ). When the limb to be examined moves during the procedure, the lines parallel to the limb may simulate periosteal reaction (Figure 2c).
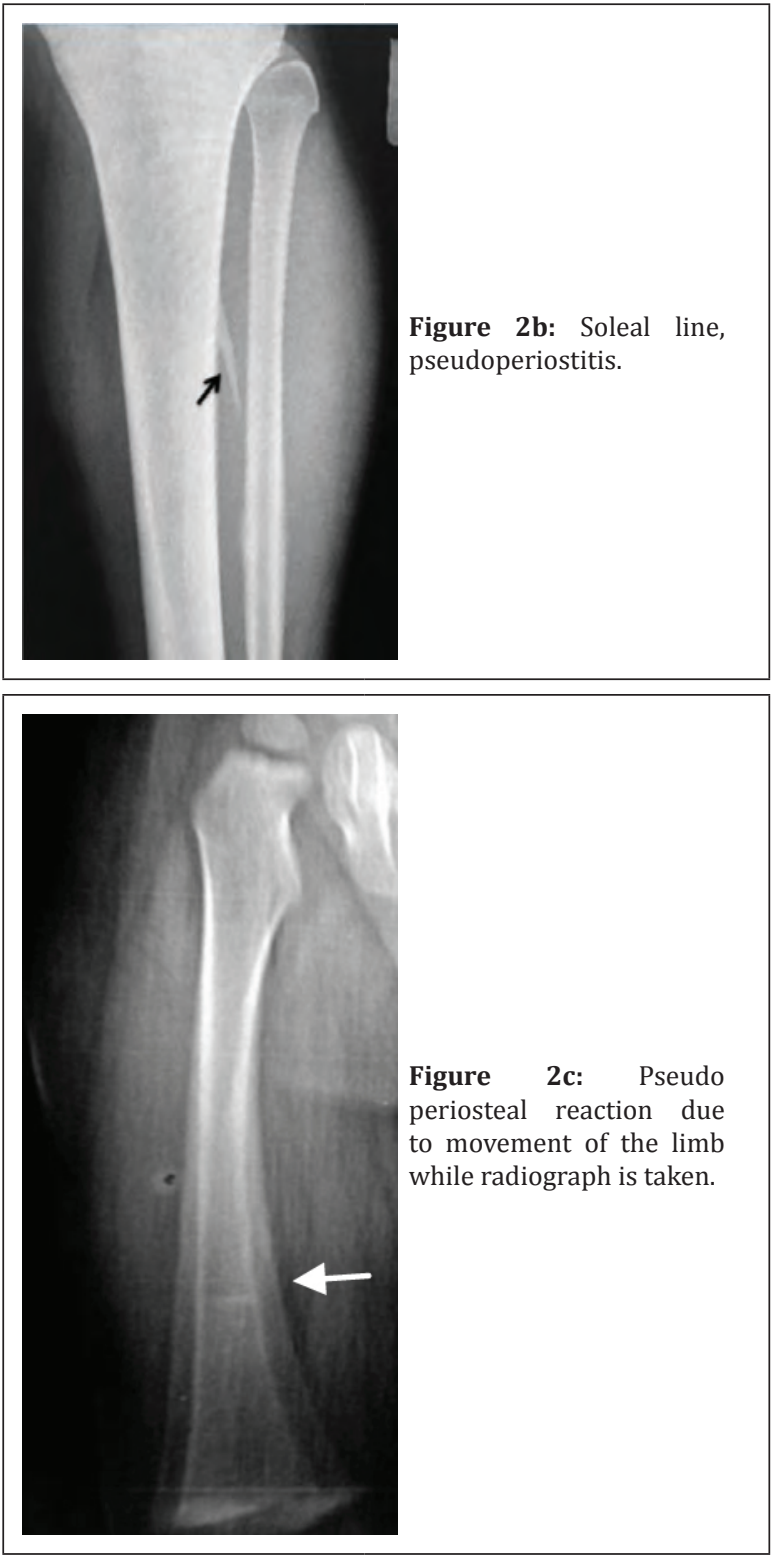

\section{Traumatic}

In the healing process of a fracture periosteal reaction is noted as a reparative process. Starting as unilaminar, it evolves into compact lesion [5]. Periosteal reaction may be the signal for trauma. The fracture line of the underlying bone may be detected later. Periosteal reaction may also be seen without a fracture of the underlying bone (Figure 3 ). 


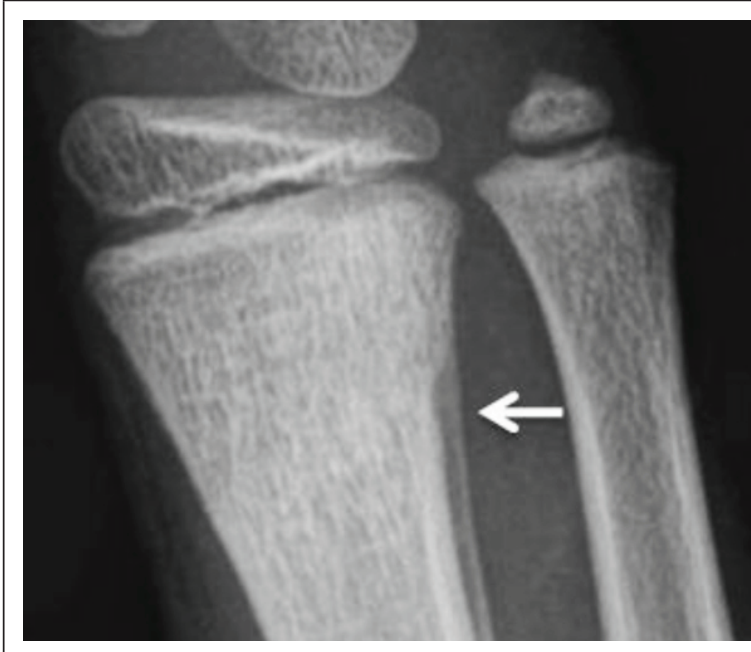

Figure 3: Periosteal reaction indicative of trauma.

\section{Cortical desmoid}

Chronic avulsion of the adductor magnus fibres at the attachment of the postero medial aspect of the lower end of the femur may simulate a tumor (Figure 4) [6].
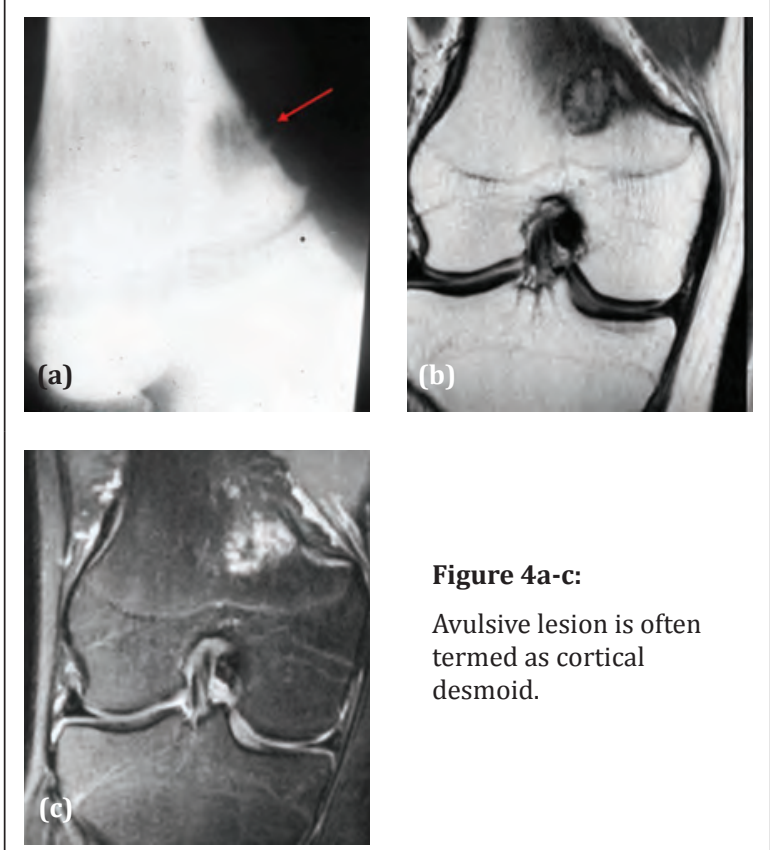

\section{Figure 4a-c:}

Avulsive lesion is often termed as cortical desmoid.

\section{Stress fractures}

A stress fracture refers to a fracture occurring in bone due to a mismatch of bone strength and chronic mechanical stress placed upon the bone. It can either be fatigue fracture: abnormal stresses on normal bone or insufficiency fracture: normal stresses on abnormal bone.
In athletes, professional dancers, in military recruits and other professionals where chronic stress is involved, a stress fracture occurs and in the process of healing periosteal reaction is noted (Figure 5a-f). In fact, periosteal reaction may be the first signal to be considered in stress fracture. To start with, endosteal or periosteal callus is seen without a fracture line, later circumferential periosteal reaction is noted with a fracture line through one of the cortical margins [7].

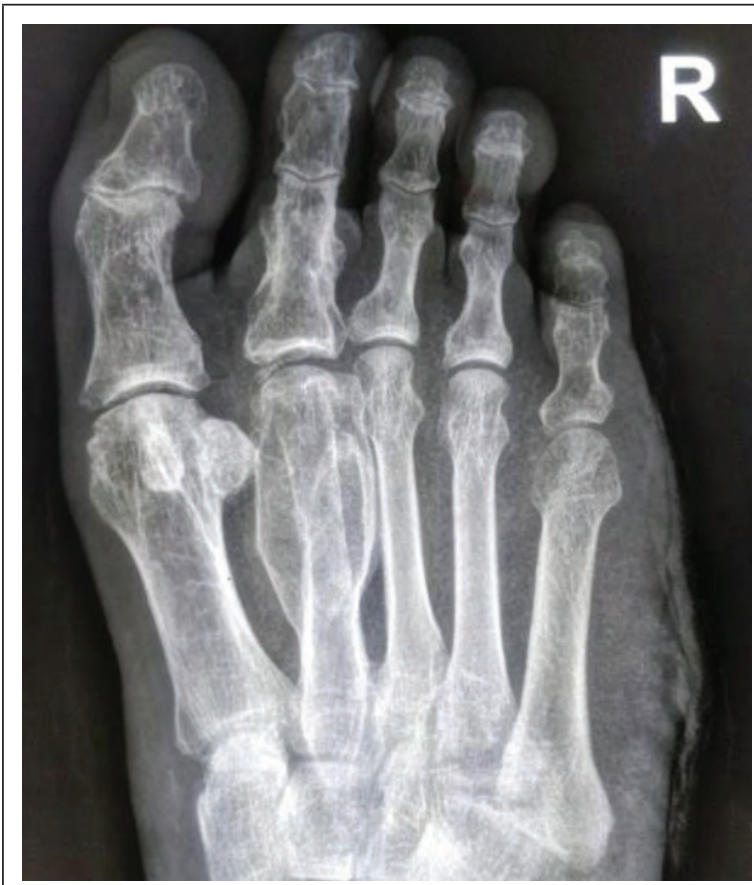

Figure 5a: Periosteal reaction in $2^{\text {nd }}$ metatarsal due to healing stress lesion.

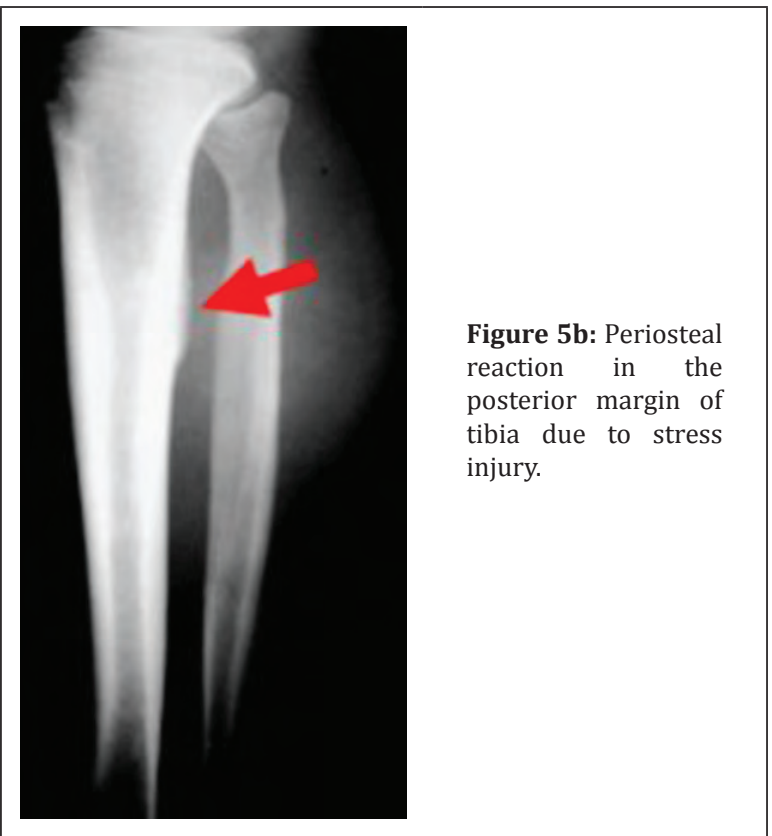



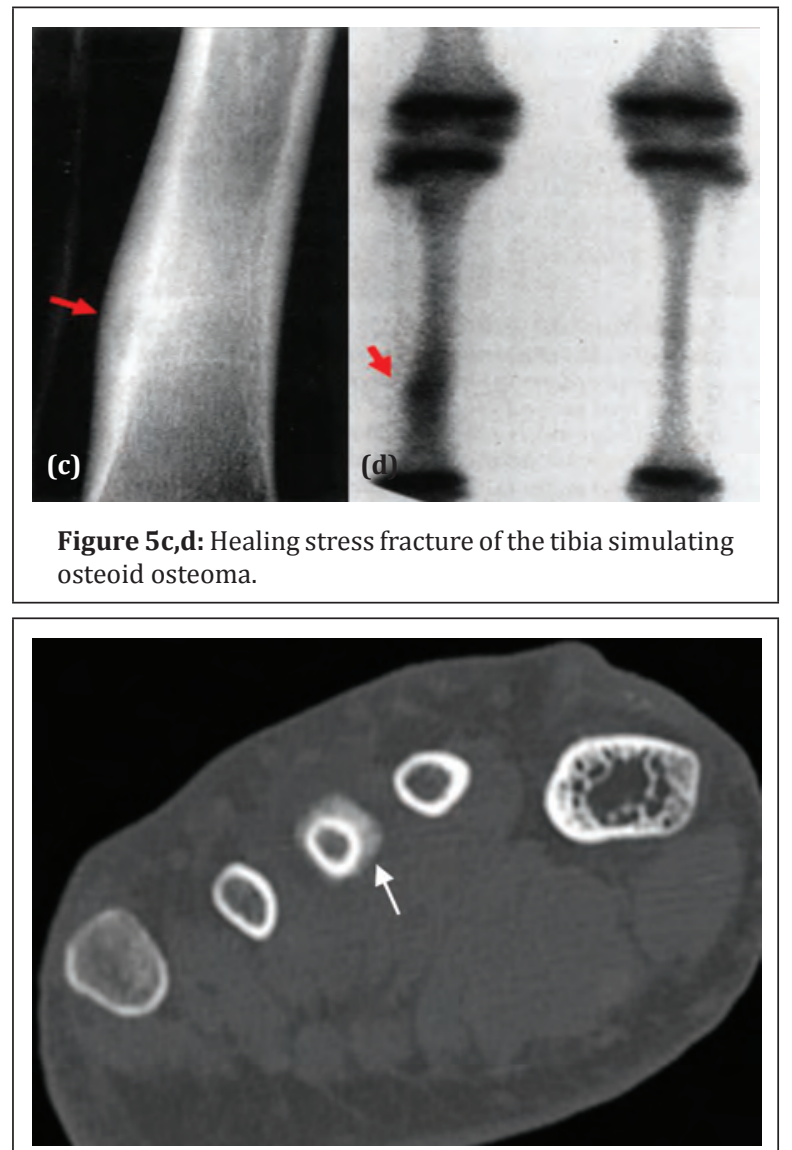

Figure 5e: CT - Periosteal reaction in healing stress fracture $3^{\text {rd }}$ metatarsal.

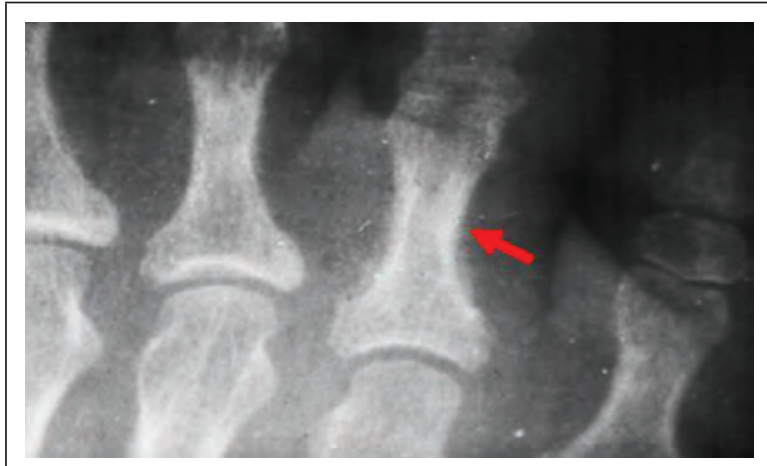

Figure 5f: Bilateral periosteal reaction of stress injury in the proximal digit of the $4^{\text {th }}$ toe.

Shin splints - Medial tibial stress syndrome, inflammatory changes occur along inner aspect of shin bone, which may result in tibial traction periostitis [8].

\section{Insufficiency fractures}

These occur when there is poor bone such as seen in old age, steroid therapy and other causes of osteoporosis (Figure 5g).

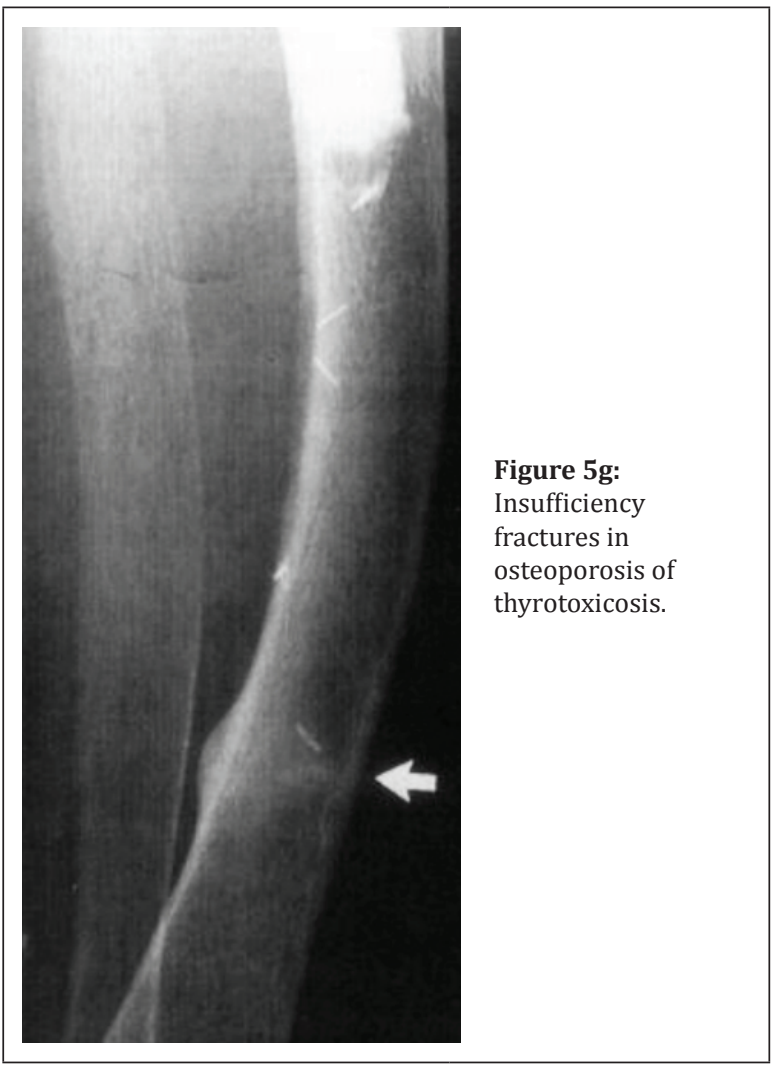

\section{Inflammatory lesions}

In inflammatory lesions, such as Langerhans cell histiocytic granuloma, erosion of the cortex may produce periosteal reaction depending upon the stage. The periosteal reaction may be multilaminar or compact (Figure 6a,b) [9].

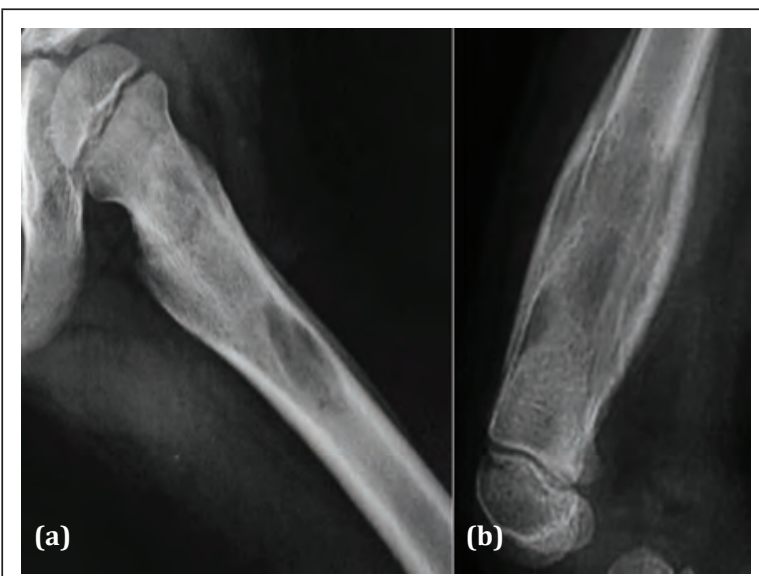

Figure 6a,b: Eosinophilic granuloma with compact periosteal reaction.

In psoriasis, Reiter syndrome and occasionally in active rheumatoid arthritis periosteal reaction may be noted (Figure 6c-e). 

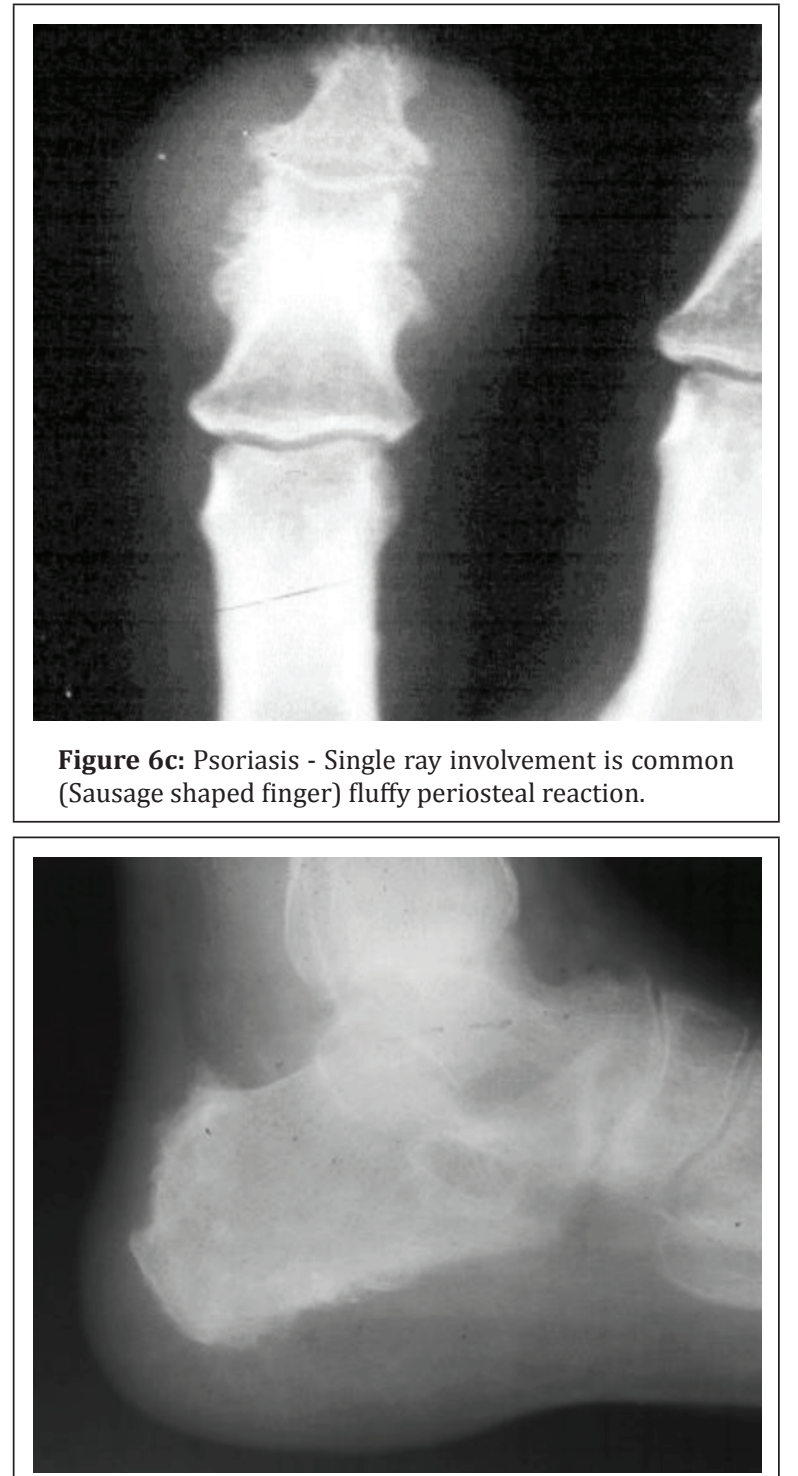

Figure 6d: Fluffy periosteal reaction and reactive new bone in the calcaneum in Reiter's syndrome.

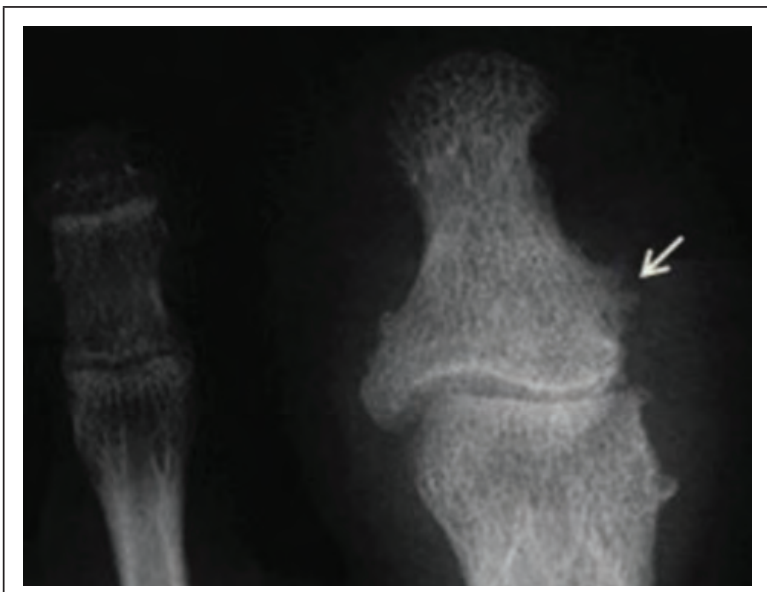

Figure 6e: Shaggy periosteal reaction in Reiter syndrome.

\section{Infections [10]}

Several pyogenic bacterial, fungal, spirochetel and parasitic organisms may induce early osteomyelitis and produce reactive periosteal reaction. In acute type, it is generally laminar and in subacute it is compact (Figure 7a-d). In subacute osteomyelitis and in Brodie's abscess periosteal reaction may also be noted. In chronic osteomyelitis thick irregular and compact periosteal reactions are noted (Figure 7e-i). In osteomyelitis of bone, several patterns of periosteal reaction are noted depending upon the stage. In Leprosy and tuberculosis periosteal reaction is noted (Figure $7 \mathrm{j}, \mathrm{k}$ ). In reactivation of chronic osteomyelitis linear periosteal reaction may be seen when there is activity. Since, fungal infections are chronic and indolent, thick spiculated periosteal reaction is noted (Figure 8). In syphilis, linear periosteal reaction is noted in congenital and secondary forms. Spiculated reaction is seen in tertiary stage (Gumma) (Figure 9d).
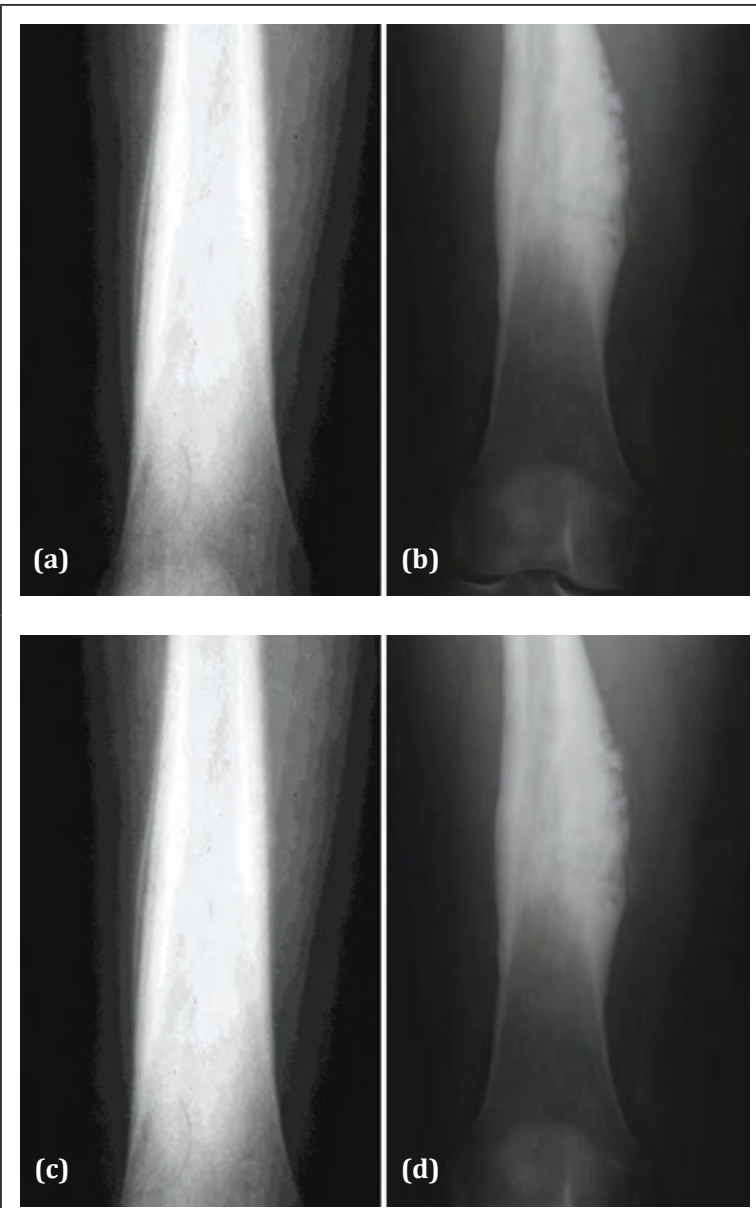

Figure 7a-d: Osteomyelitis, (a) thin periosteal reaction, (b) thick periosteal reaction, (c,d) bizarre. 


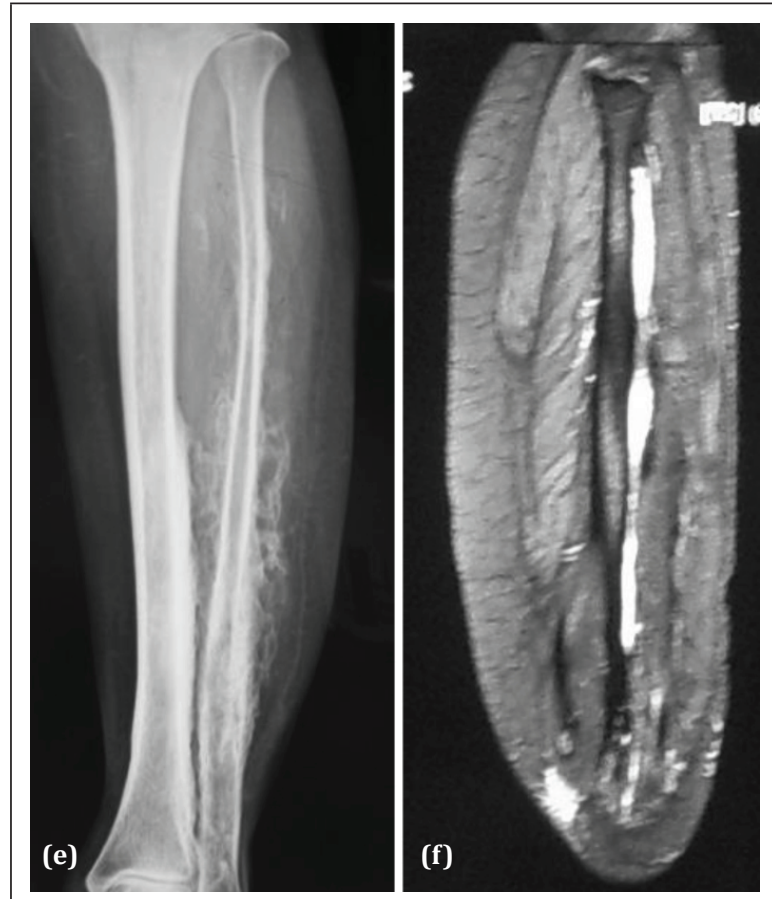

Figure 7e,f: Bizarre periosteal reaction, (e) Radiograph, (f) MRI chronic osteomyelitis with myositis.

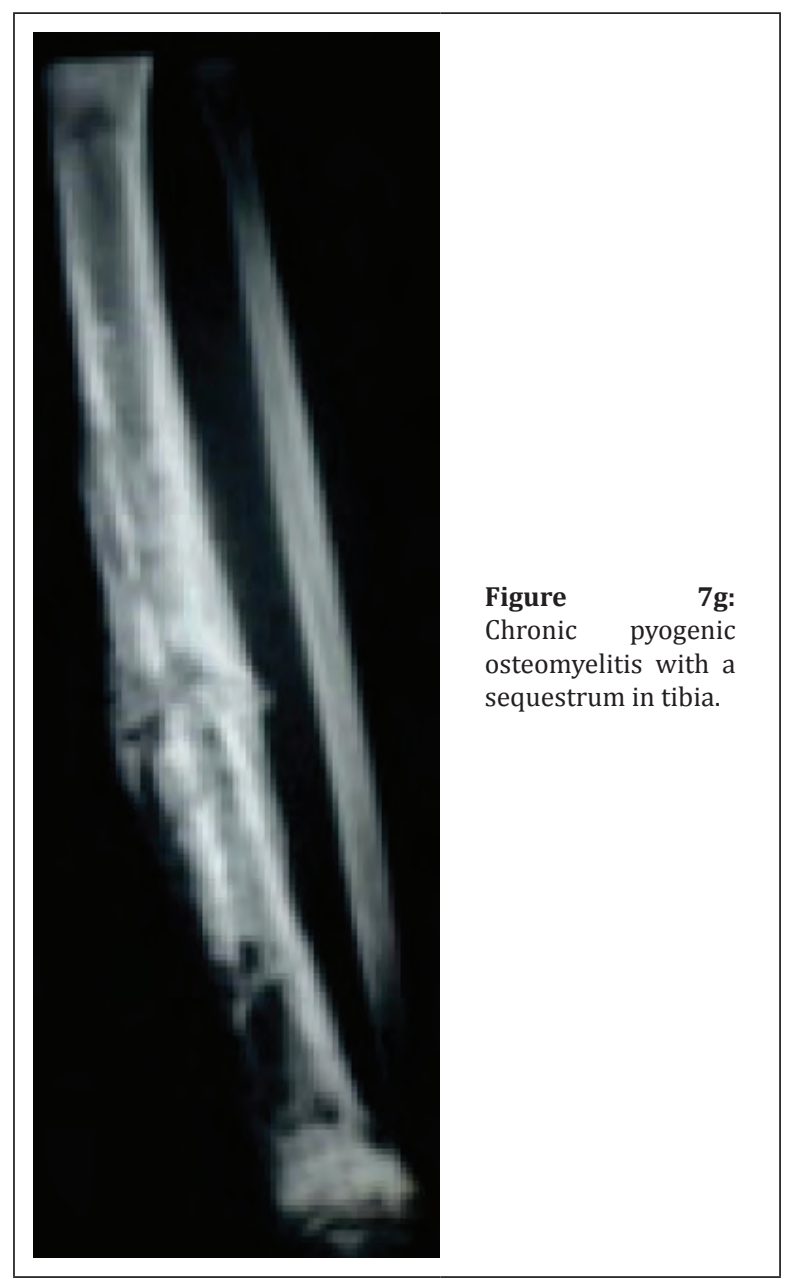

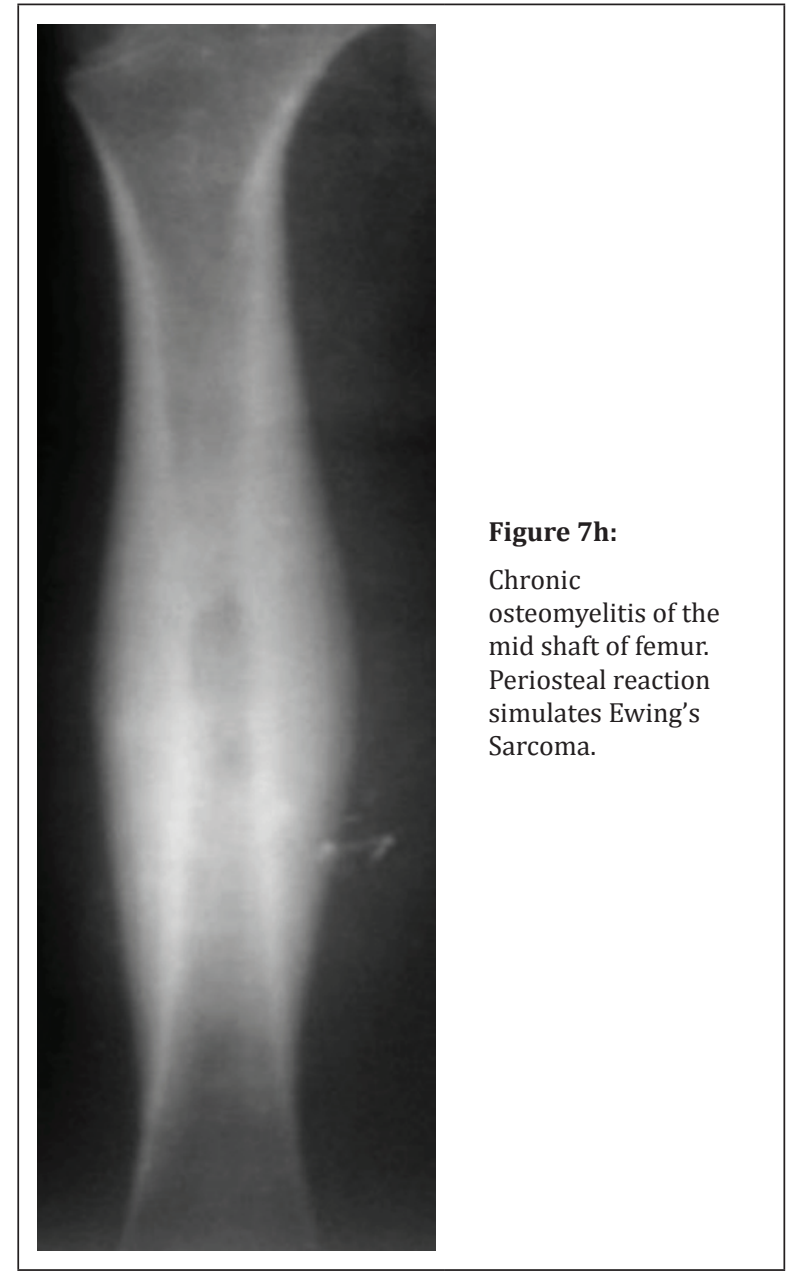

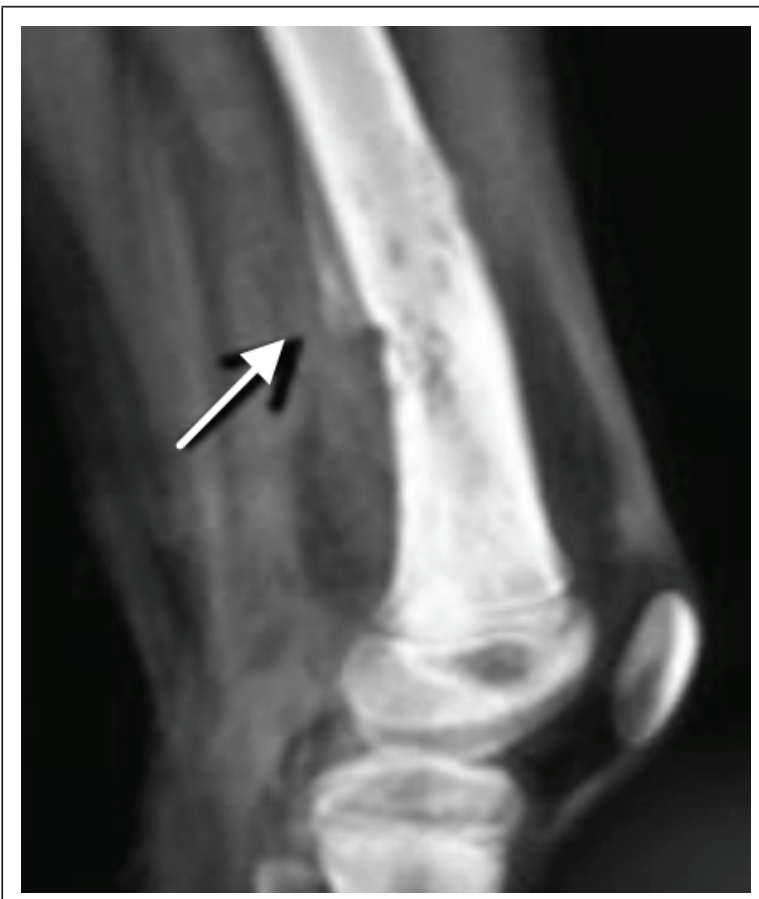

Figure 7i: Pyogenic osteomyelitis with fracture. Note Codman's triangle. 

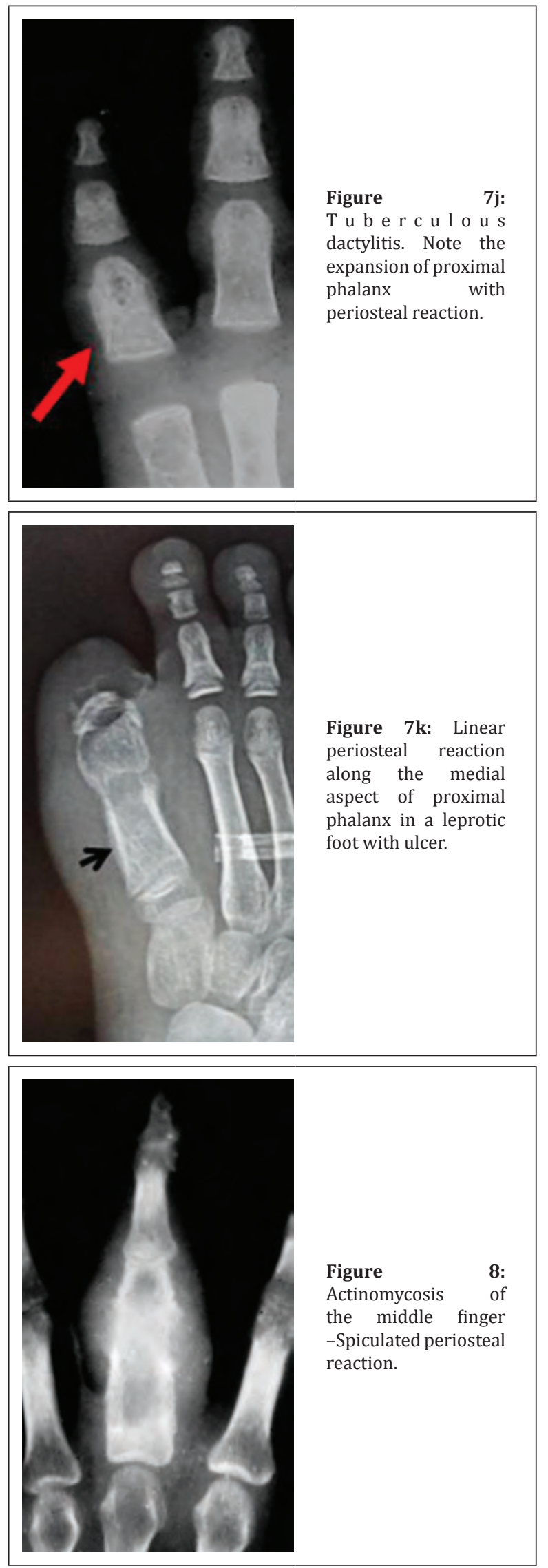

\section{Syphilis}

Periosteal reaction is noted in congenital syphilis, secondary and tertiary syphilis. In congenital syphilis, osteomyelitis and osteochondritis are common and the periosteal reaction is usually thin and compact (Figure 9a,b). In secondary syphilis, diaphyseal osteomyelitis and periosteal reaction are noted (Figure 9c). A saber shin deformity of chronic osteoperiostitis and bowing of the upper half of the tibia is seen in tertiary syphilis (Figure 9d).

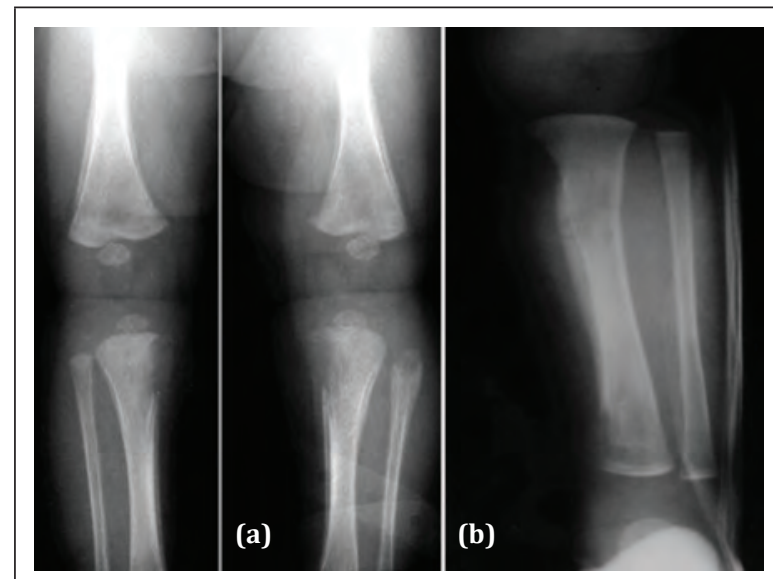

Figure 9a: Congenital syphilis periosteal reaction along the (a) femora and (b) radius.

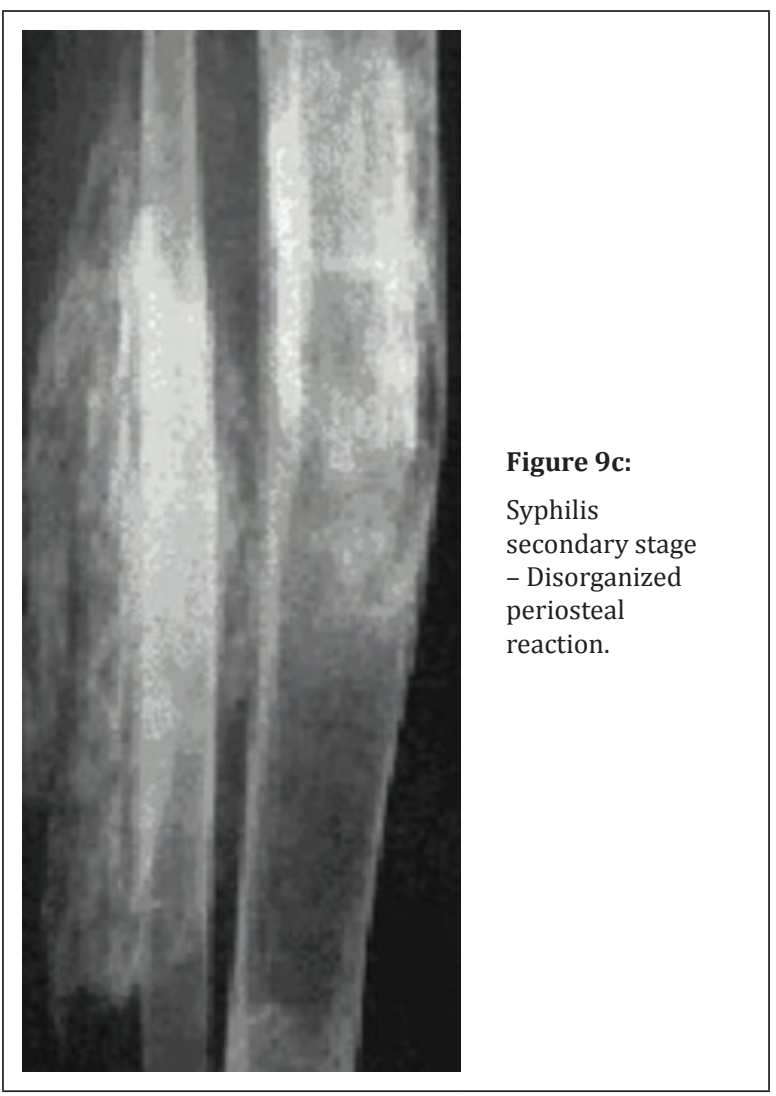




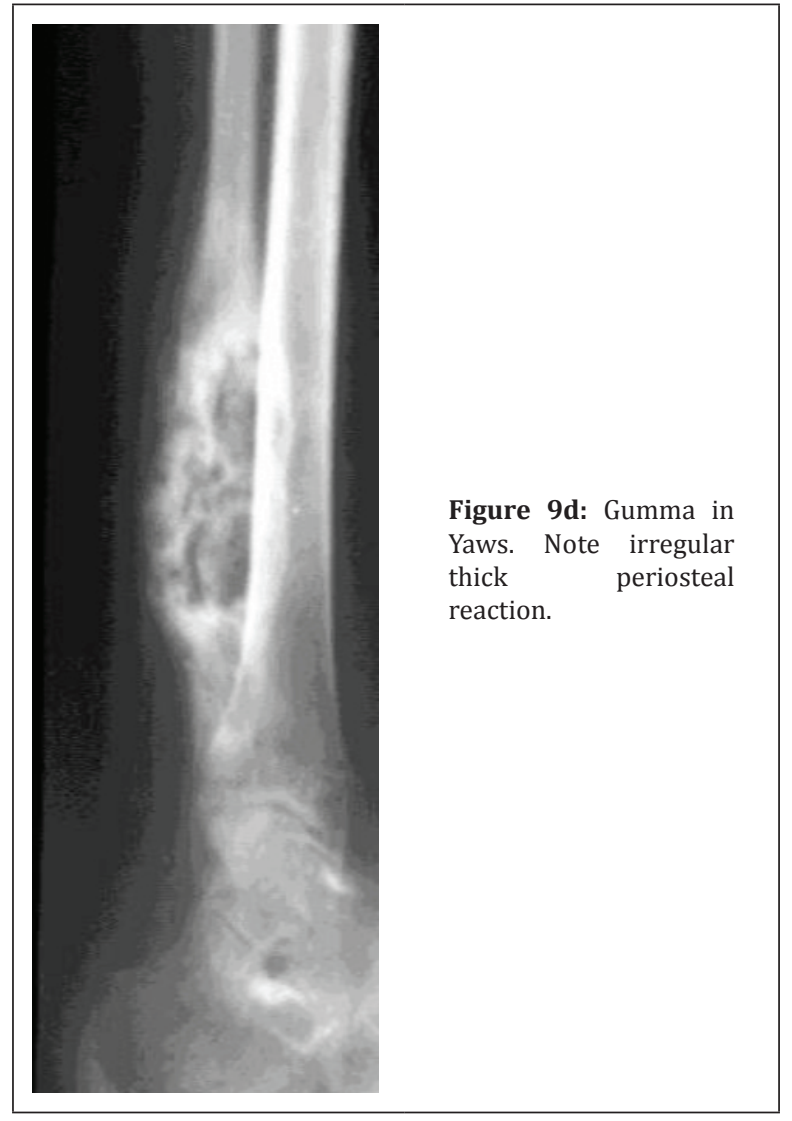

\section{Bone infarcts}

Bone infarcts resulting from steroid therapy, sickle cell anaemia, Gaucher disease etc., may produce periosteal reaction in addition to medullary changes (Figure 10a,b) [11].

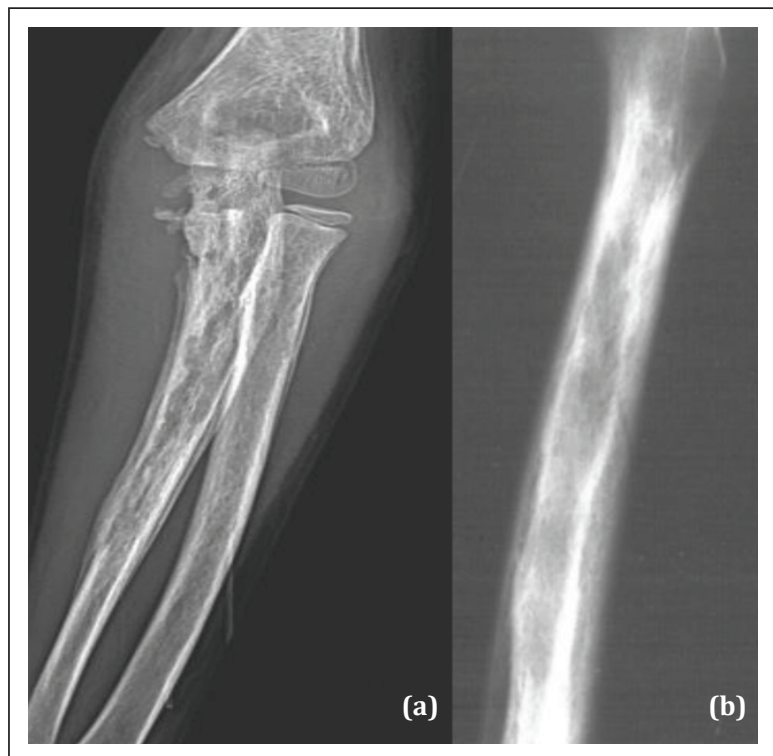

Figure 10a, b: Linear periosteal reaction osteomyelitis, (a) sickle cell anemia, (b) infarct in sickle cell.
Spiculated periosteal reaction may be seen in several entities which are listed in Table 4.

Table 4: Spiculated (sunburst periosteal reaction).

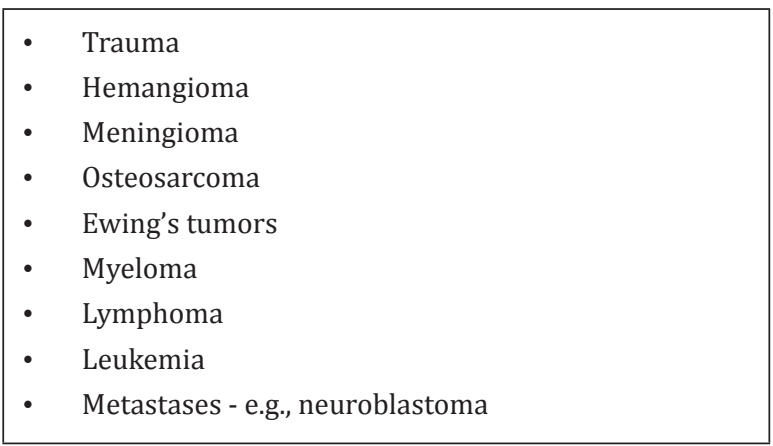

\section{Idiopathic}

In Caffey's, (idiopathic cortical hyperostosis) disease, periosteal reaction is noted along the mandible, clavicles, ribs and long bones of the extremities (Figure 11). Periosteal reactions which are linear and thinner to begin with, become thicker and merge with the cortex indicating hyperostosis [12].

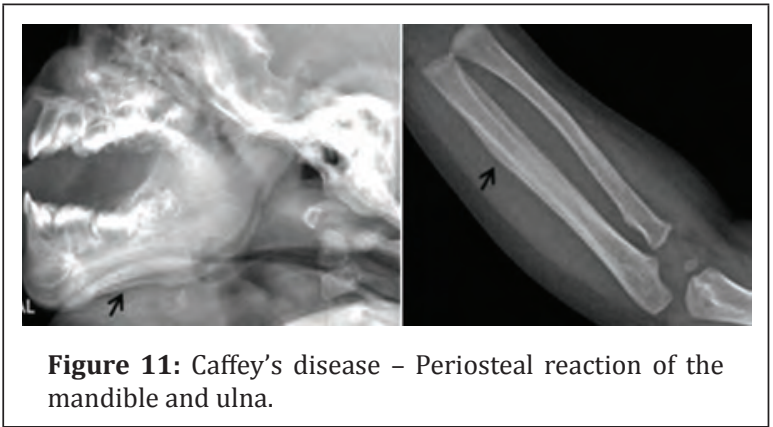

\section{Hypertrophic osteoarthropathy - Primary, secondary}

\section{Primary hypertrophic osteoarthropathy}

Primary hypertrophic osteoarthropathy (Pachydermoperiostosis) is familial without a known cause. Pachydermoperiostosis (PDP)/ Touraine-Solente-Gole syndrome is the primary form \& accounts for 5\% of all cases of hypertrophic osteoarthropathy. Mixed type of periosteal reaction is noted not only along tubular bones but also cuboidal bones like tarsus (Figure 12a-d). It is idiopathic and is familial. This is generally a component by the thickening of the skin. Radiographic features include extensive periosteal new bone formation involving all long bones. The outer surface of the new bone tends to be irregular and spiculated in some cases [13]. 


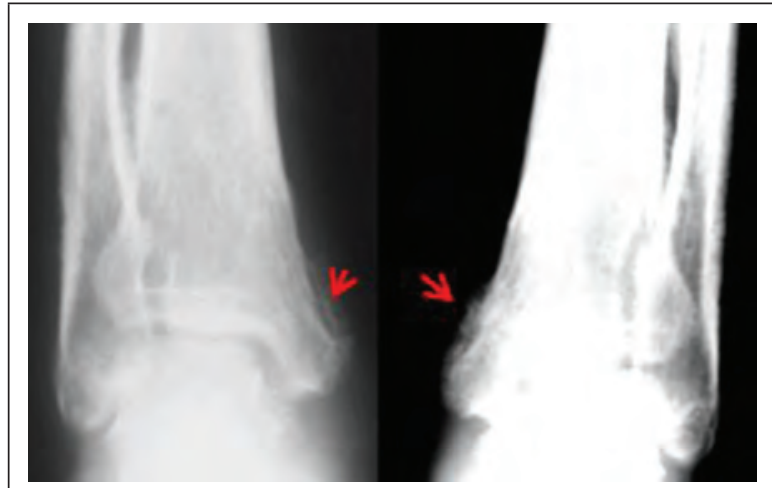

Figure 12a: Pachydermoperiostosis involving the ankle bones.
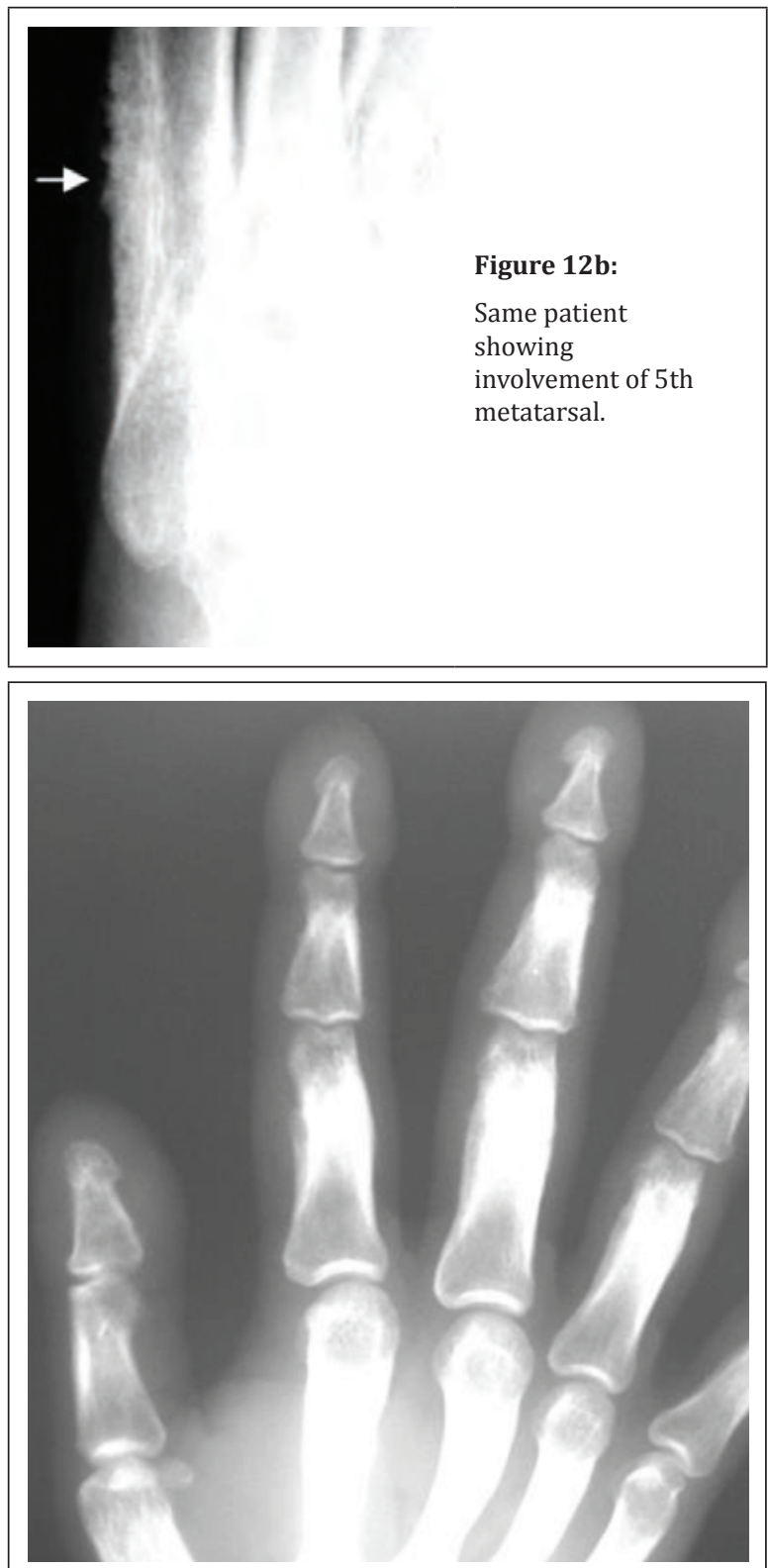

Figure 12c: Same patient showing involvement of metacarpals and phalanges.

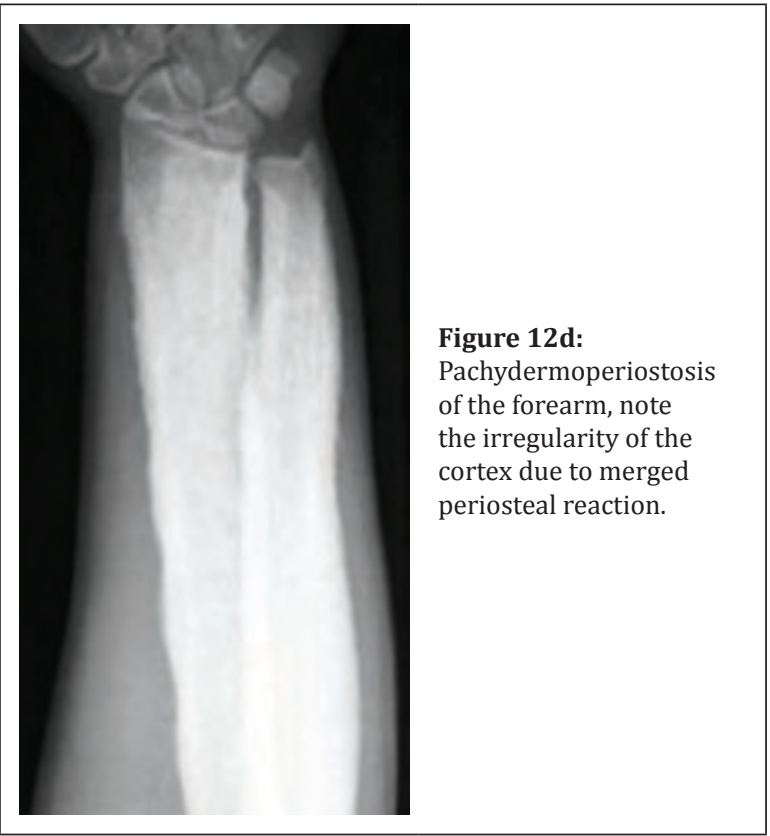

\section{Secondary hypertrophic osteoarthropathyis}

Secondary hypertrophic osteoarthropathyis characterized by clubbing of the digits. Secondary hypertrophic osteoarthropathy is due to several thoracic and extra thoracic causes (Figure 13a,b). The thoracic causes include bronchogenic carcinoma, Mesothelioma, pleural fibroma, empyema, bronchiectasis, fungal infections, etc. Extra thoracic causes are related to the systemic areas such as ulcerative colitis and other disorders of small bowel and large bowel. Radiologically, the early change is thin periosteal proliferation or new bone. In later stages there is undulated, irregular and rough type of periosteal reaction is noted. In fact, all types of periosteal reaction are noted depending upon the stage of the disease [14].

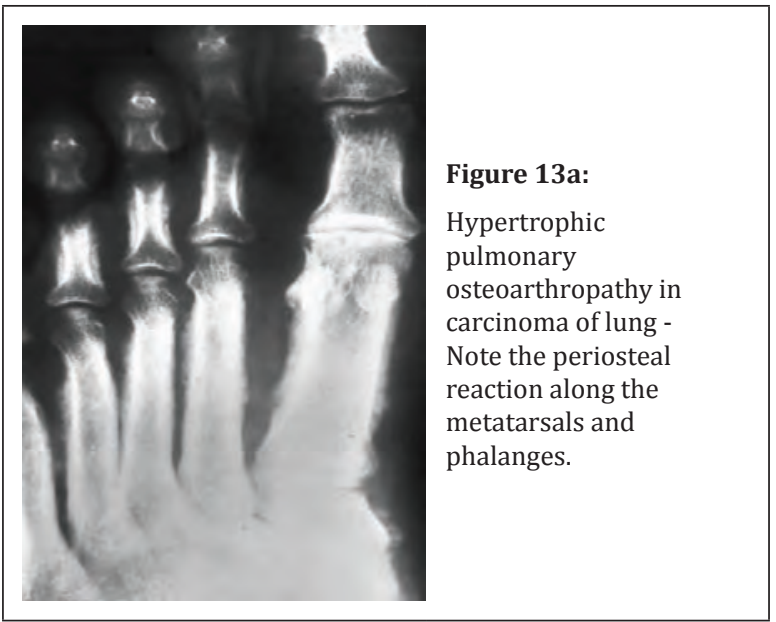




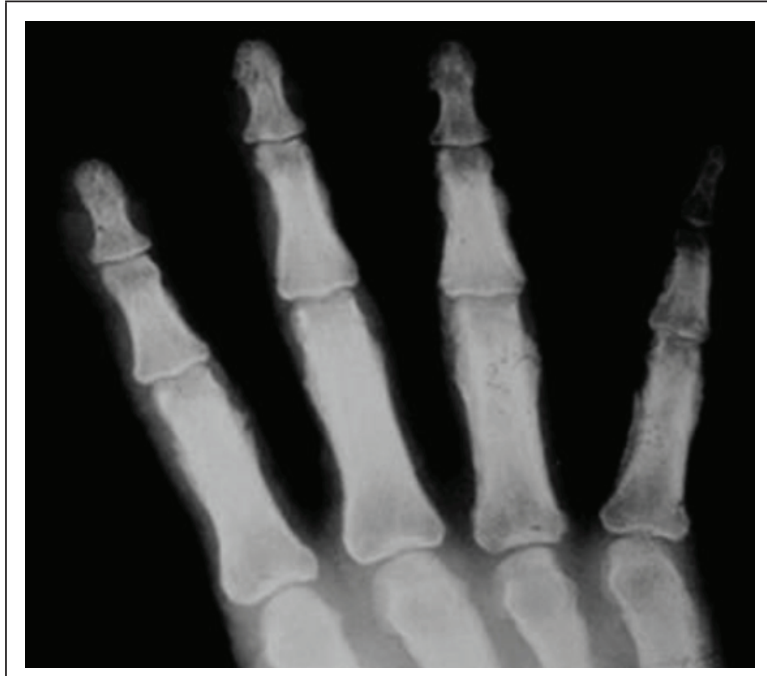

Figure 13b: Hypertrophic osteoarthropathy - Carcinoma lung.

\section{Medications}

It is well known that prostaglandin therapy for closure of patent ductus arteriosus is administered often and this may induce periosteal reaction along long bones [15].

\section{Nutritional}

The most common nutritional deficiency that causes periosteal reaction and subperiosteal hematoma in vitamin ' $C$ ' resulting in scurvy (Figure 14a,b). In vitamin ' $\mathrm{D}$ ' deficiency, in the reparative phase periosteal reaction may be noted (Figure 14c) [16].

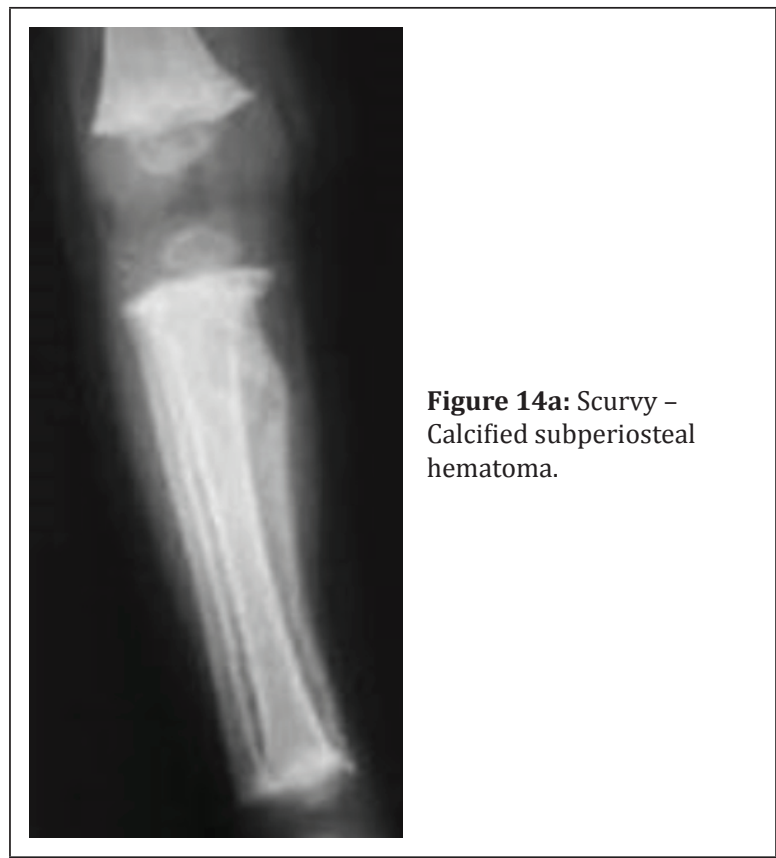

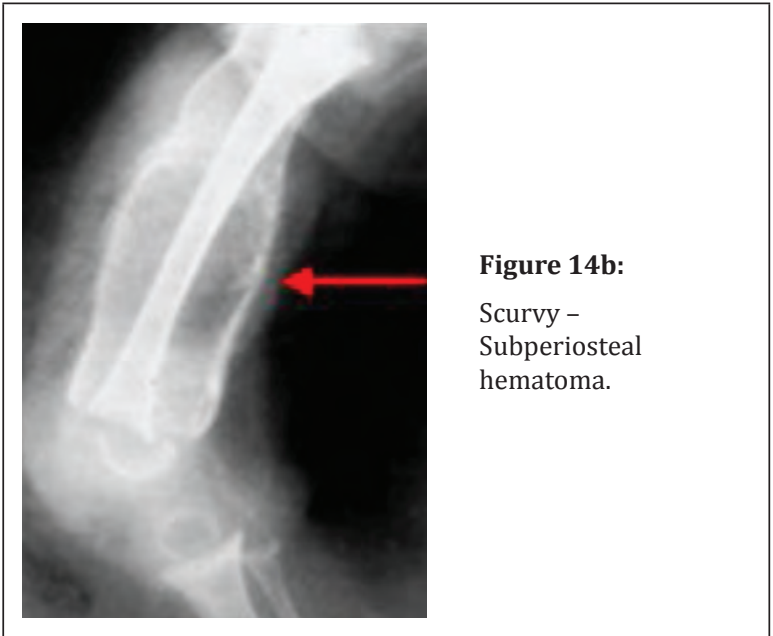

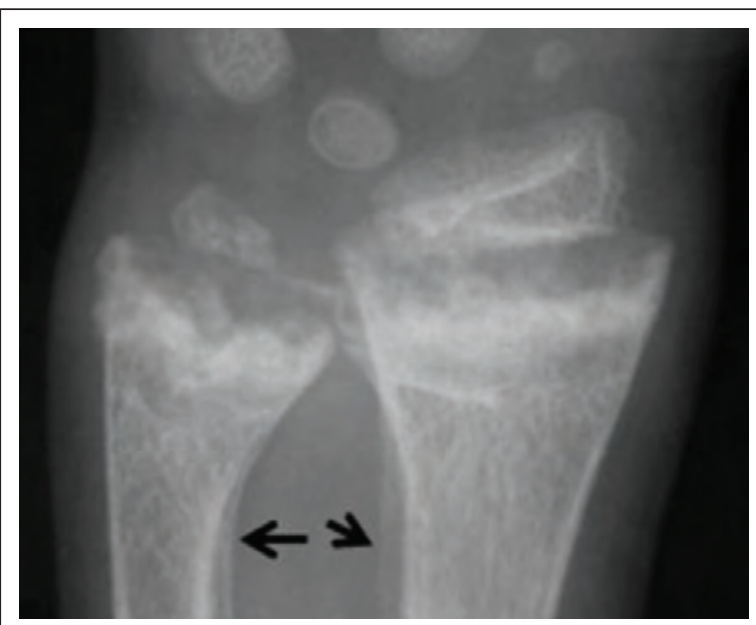

Figure 14c: Healing rickets - Paint brush appearance with periosteal reaction along the interosseous margins.

\section{Metabolic \& endocrinal}

In renal osteodystrophy with secondary hyperparathyroidism periosteal reaction may be noted. In corticosteroid therapy, periosteal reaction may be noted as a reparative process resulting in hypercallosis (Figure 15a).

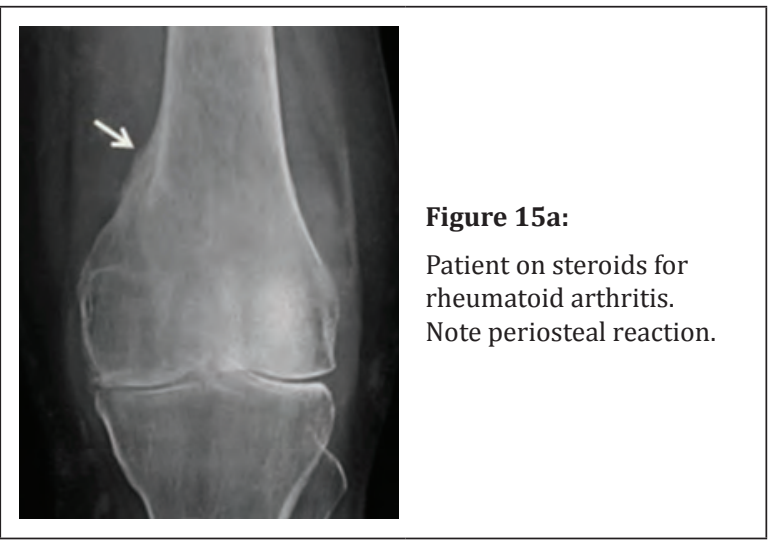


Thyroid acropachy is a rare and late manifestation of treated hyperthyroidism associated with swelling of the extremities and clubbing of the fingers and toes. Periosteal reaction of the tubular bones of the digits of the feet and hands is confined to the diaphysis. This periosteal reaction is irregular and lacy. The bones most frequently affected include the $1^{\text {st }}, 2^{\text {nd }}$ and 5 th metacarpals, the proximal and middle phalanges of the fingers, the $1^{\text {st }}$ metatarsal and the proximal phalanges of the toes. Thyroid acropachy is known to induce periosteal reaction along the thumb, other bones of the hands and feet as well as tibiae (Figure $15 b, c)[17]$.

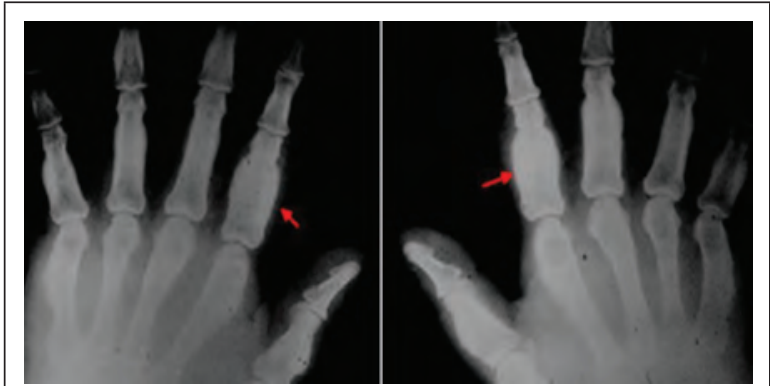

Figure 15b: Thyroid acropachy - Asymmetrical periosteal reaction along the phalanges.

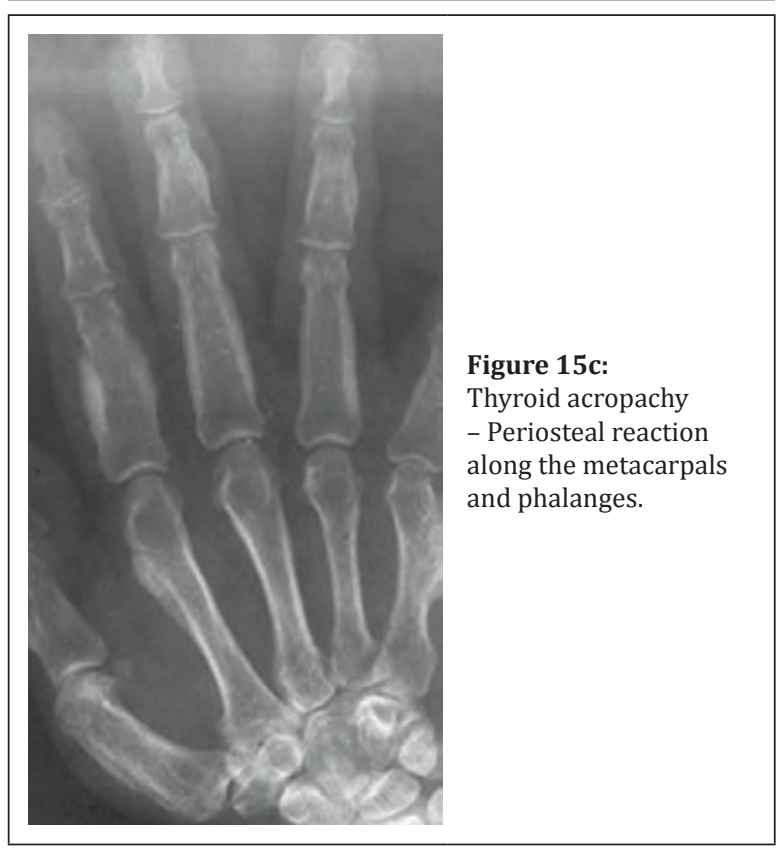

Renal osteodystrophy is a clinicoradiological syndrome which includes osteosclerosis, osteoporosis, osteomalacia, secondary hyperparathyroidism and soft tissue calcification. But on occasion, periosteal reaction is also noted with osteosclerosis (Figure 15d).

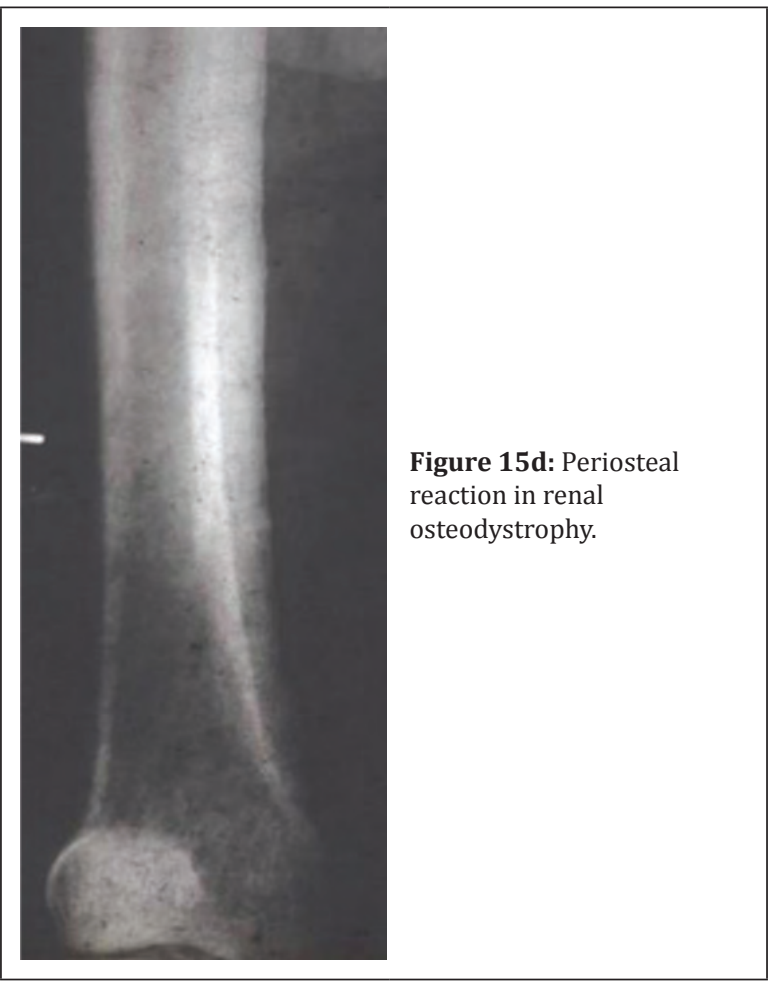

\section{Toxic}

Hypervitaminosis 'A' can cause solid periosteal reaction in long bones, most commonly affecting the ulna, lower leg, metatarsals and clavicle, and rarely the mandible. In hypervitaminosis ' $\mathrm{A}$ ' periosteal reaction has been described along the medial border of ulna and lateral border of $5^{\text {th }}$ metatarsal (Figure 16a).

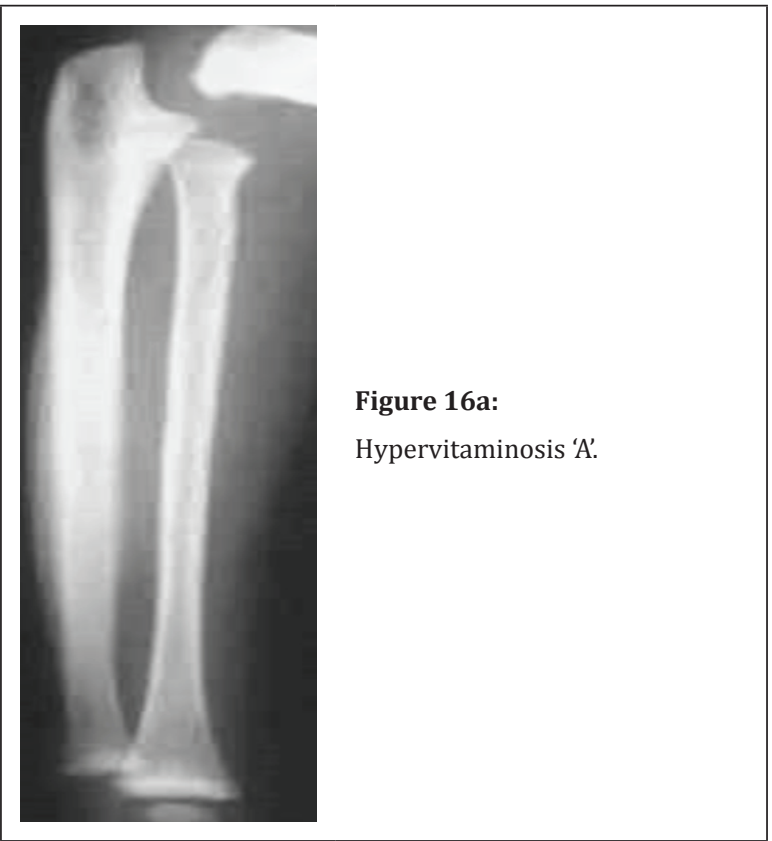


In fluorosis, periosteal reaction is present in a haphazardmanner with spikes and exostotic excrescences (Figure 16b-e) [18].
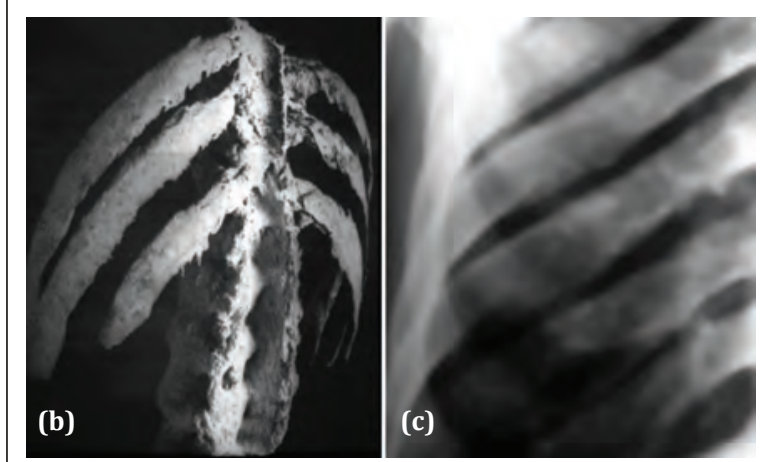

Figure 16b,c: (b) Specimen, (c) Radiography of ribs -Fluorosis - Saw tooth appearance of borders of ribs.

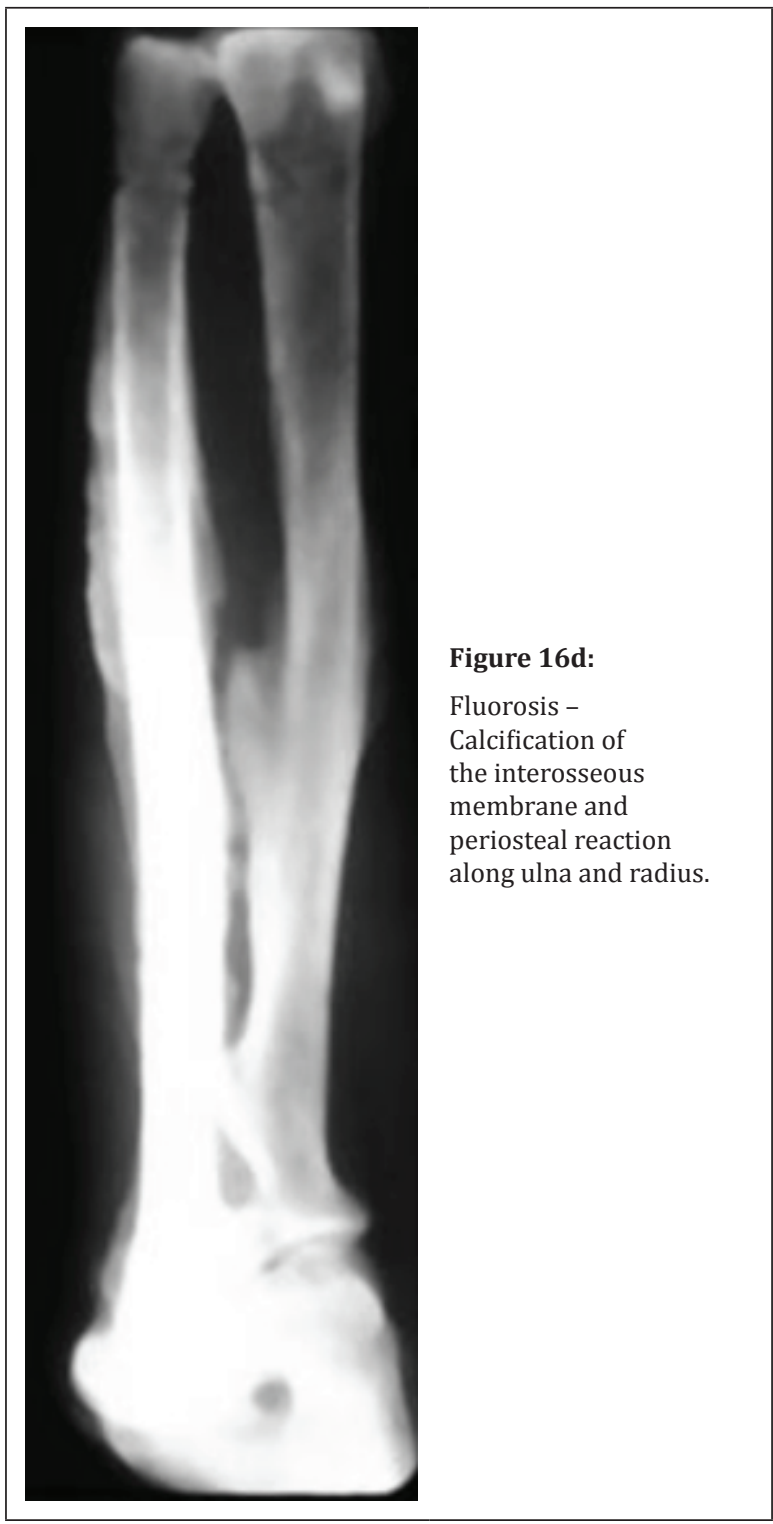

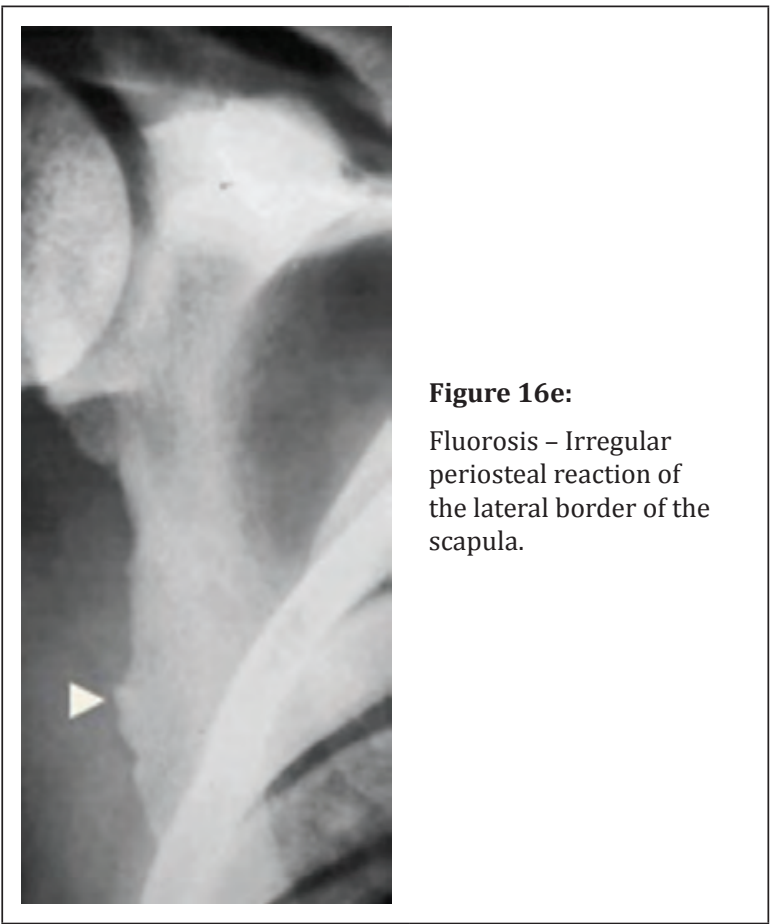

\section{Vascular insufficiency}

The periosteal reaction in these cases is thick and dense. The free edges are often undulated and rough. Associated soft tissue inspection may contribute to the periosteal reaction.

Varicositis of the lower extremities may produce thin and dense periosteal reaction. In cases with ulceration, rough and undulated type of periosteal reaction is noted (Figure 17a,b).

In systemic vasculitis such as periarthritisnodosa, periosteal reaction is noted and is caused by local hypoxia of bone with subsequent release of bone derived growth factors. In sarcoidosis also periosteal reaction is occasionally noted (Figure 17c) [19].

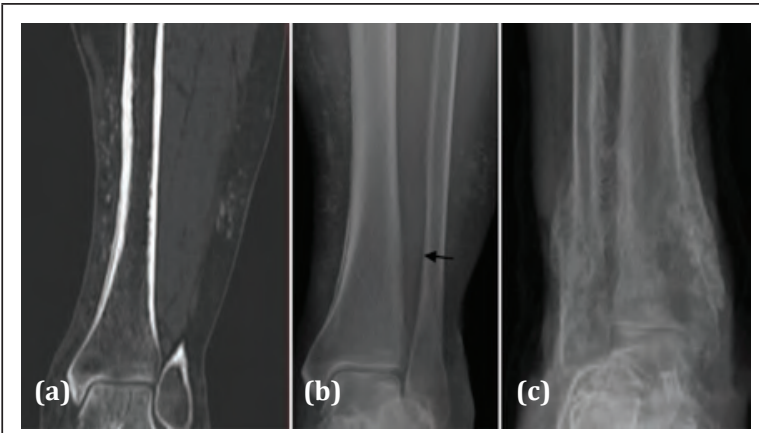

Figure 17a-c: Periosteal reaction in varicositis, (c) Vascular insufficiency. 


\section{Periosteal neoplasms - benign}

Tumors of the periosteum are rare. They can be benign or malignant. Tumors arising other than periosteum can also produce periosteal reaction $[20,21]$. In benign neoplasms of bone, particularly in osteoid osteoma, there is a small nidus $(<1.5$ $\mathrm{cm}$ ) and periosteal reaction is noted (Figure 18a) $[22,23]$. In Osteoblastoma, the radiolucent nidus is larger in diameter $(>2 \mathrm{~cm})$ and compact periosteal reaction may be noted (Figure 18b) [24].
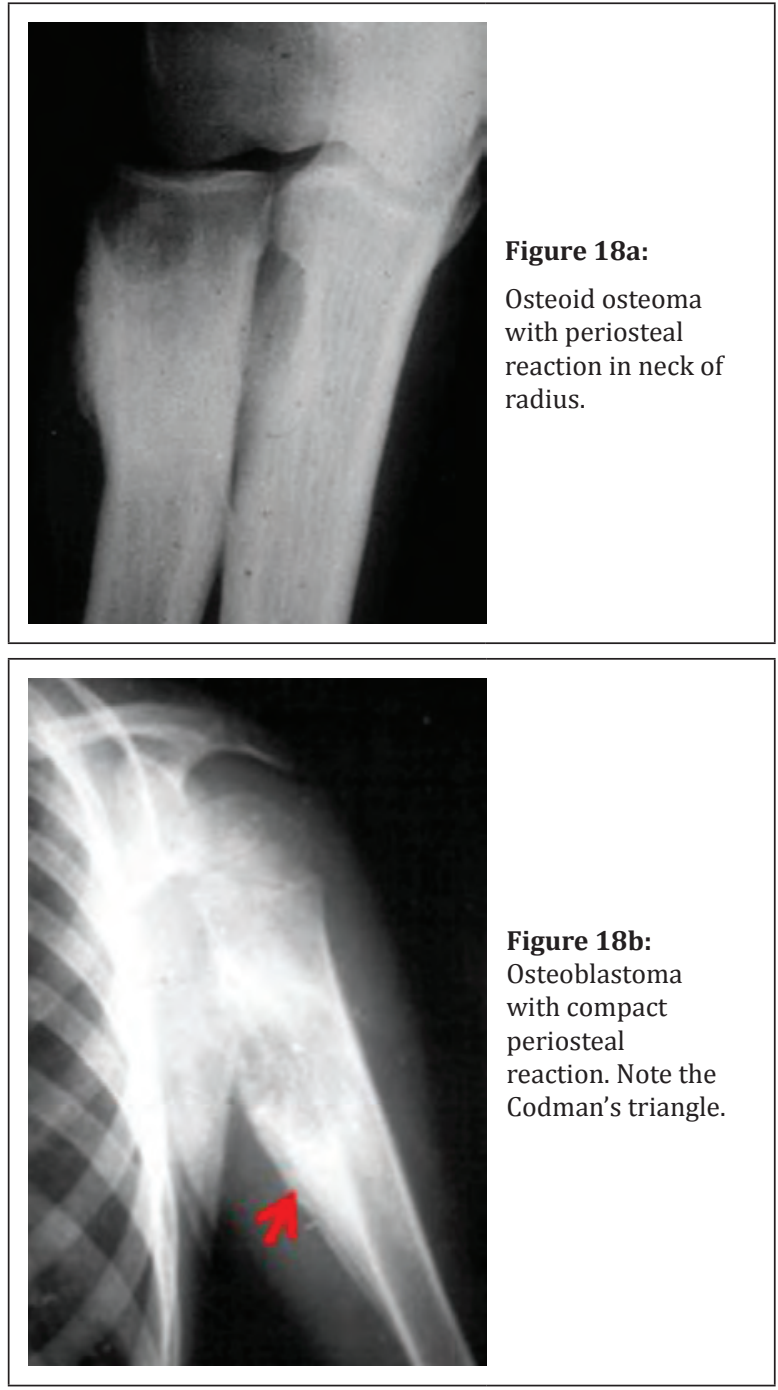

Periosteal chondroma is also called 'Juxta cortical chondroma' and is a chondromatous lesion arising from the periosteum. It may grow into the medullary cavity. A characteristic cortical hook, similar to the hook noted in gout indicates the cartilaginous nature. MRI is rarely necessary. Nodular calcification may be noted in the matrix (Figure 18c,d) [25, 26].

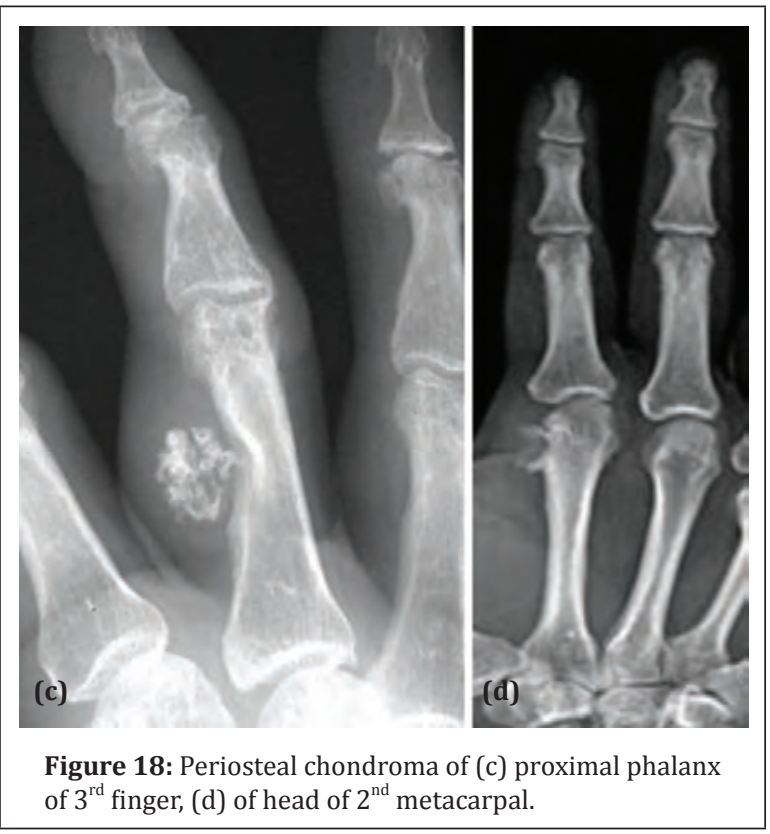

\section{Malignant neoplasms [27]}

Periosteal Osteosarcoma is a rare primary malignant bone tumor and a variant of osteosarcoma. It is a surface lesion without evidence of medullary involvement. The radiologic appearance of periosteal osteosarcoma is a broad-based surface soft-tissue mass that causes extrinsic erosion of thickened underlying diaphyseal cortex and perpendicular periosteal reaction extending into the soft-tissue component [26]. The tumour presents as nonhomogeneous masses of speculated osteoid matrix progressively denser from the periphery to their cortical base. The most common location is the proximal third of the femur. Most of the lesions are diaphyseal in location (Figure 19a) [28]. It is difficult to differentiate it from surface osteosarcoma and osteochondroma undergoing malignancy.

In primary malignant neoplasms of bone such as osteosarcoma (Figure 19b-e), chondrosarcoma (Figure 20) [29 30], fibrosarcoma, malignant fibrous histocytoma and Ewing's family of tumors, a spectrum of periosteal reactions is noted (Figure 21a-f). In Osteosarcoma, perpendicular sun-ray type of periosteal reaction is noted. The Codman's triangle which is formed by elevated periosteum, Sharpey fibres, and cortex of the bone has been described in osteosarcoma but this can be noted in other malignant and benign lesions. In infections and healing fractures also Codman's triangle can be seen (Figure 19c,d). 

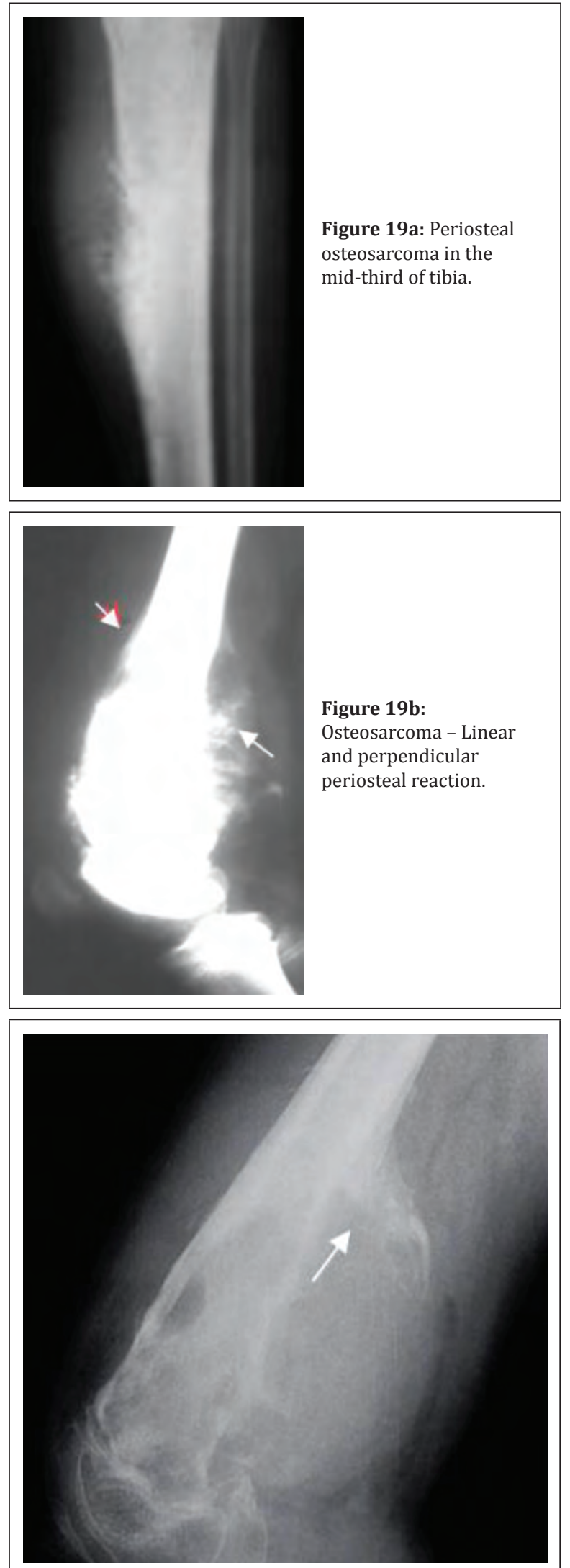

Figure 19c: Osteosarcoma. Note the thick Codman triangle with soft tissue mass.
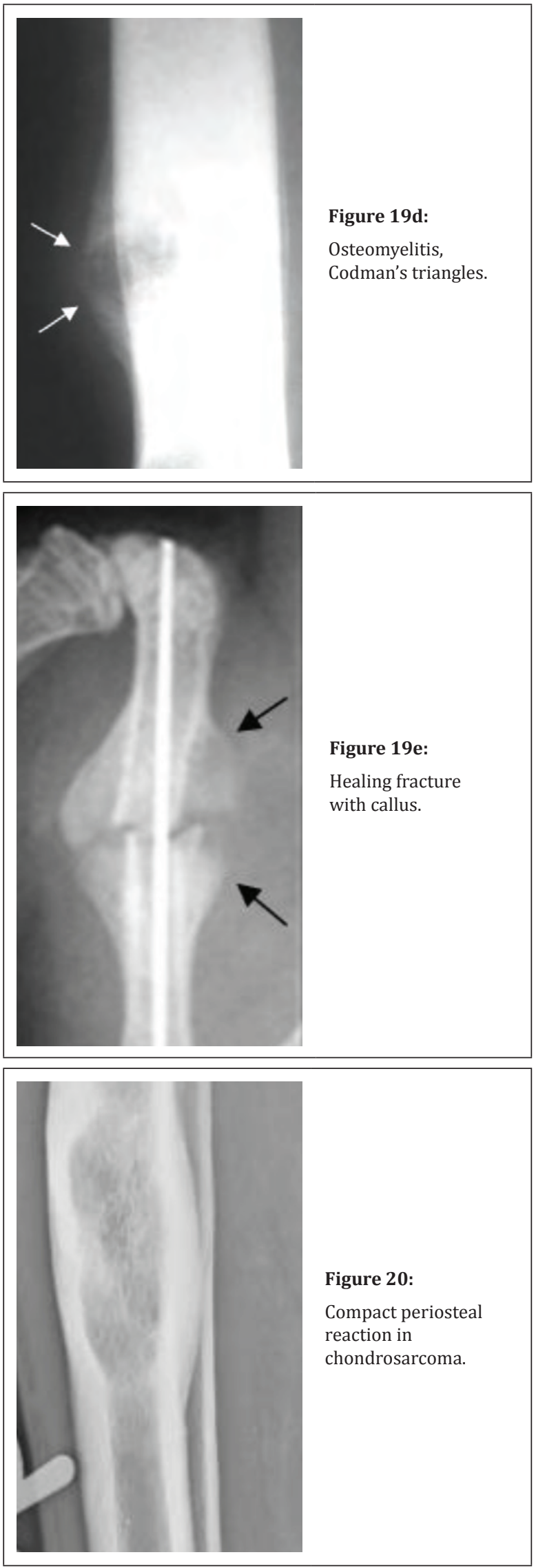


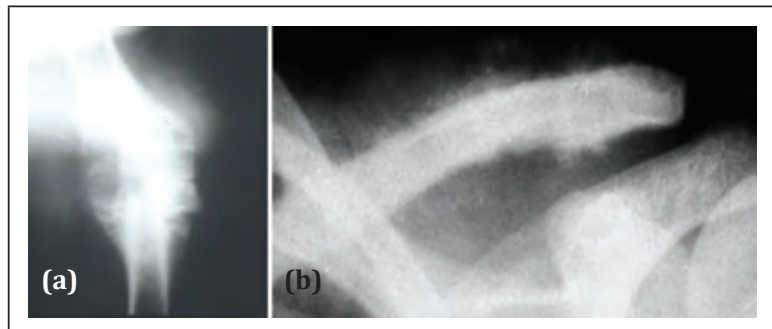

Figure 21a,b: Ewing's sarcoma with different types of periosteal reactions, (a) femur, (b) clavicle.
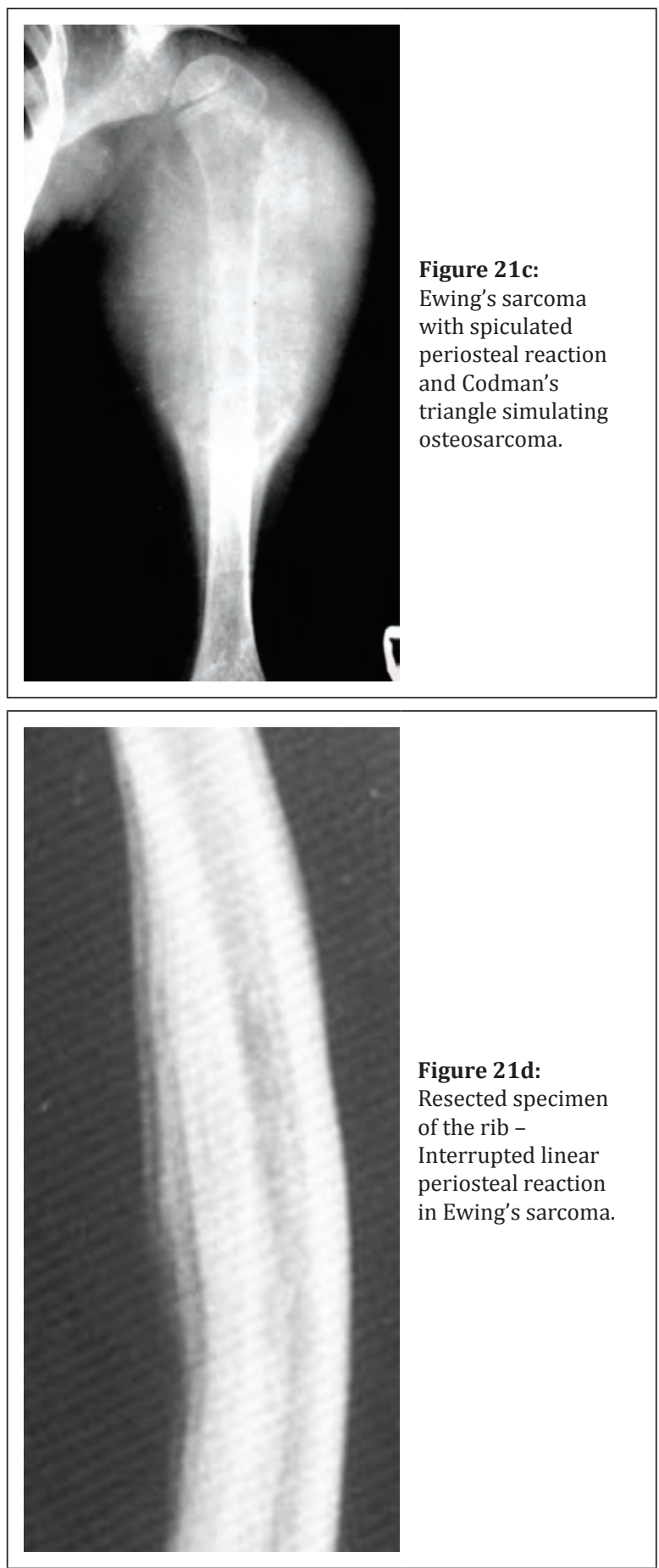

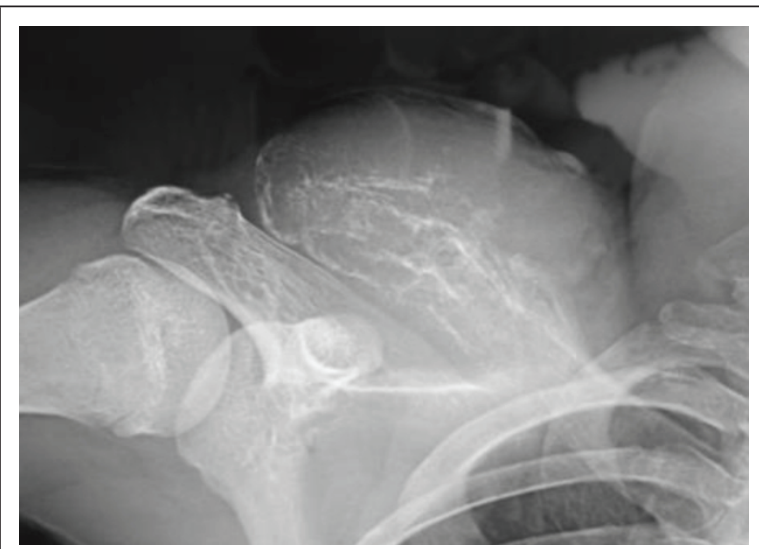

Figure 21e: Round cell tumor of clavicle with periosteal reaction.

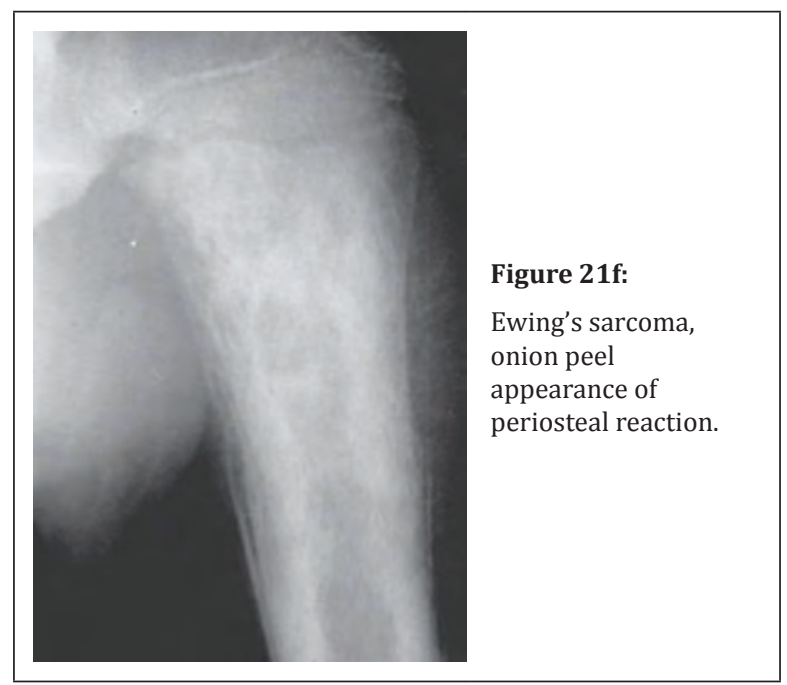

In leukaemia and lymphoma, periosteal reaction is observed [31]. In leukaemia, there is a moth-eaten appearance of bone with linear periosteal reaction at the metaphyseal areas (Figure 22a,b). Primary lymphoma of the bone is rare. The periosteal reaction is non-specific (Figure 22c).

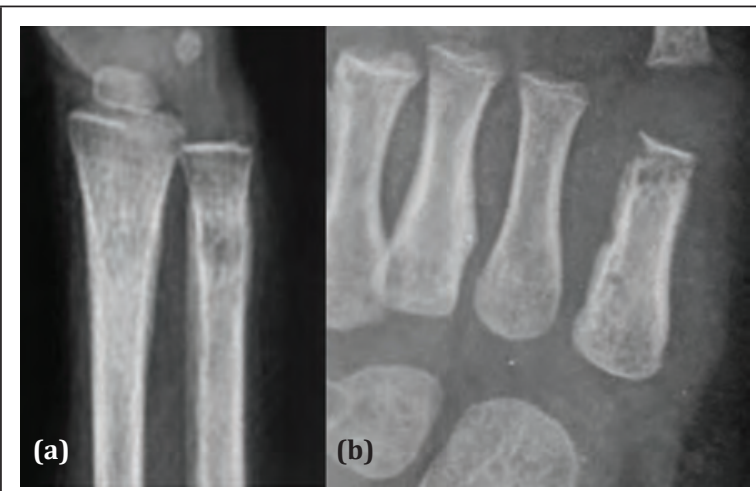

Figure 22a,b: Leukaemia, (a) - Linear periosteal reaction in radius, (b) in 5th metatarsal. 


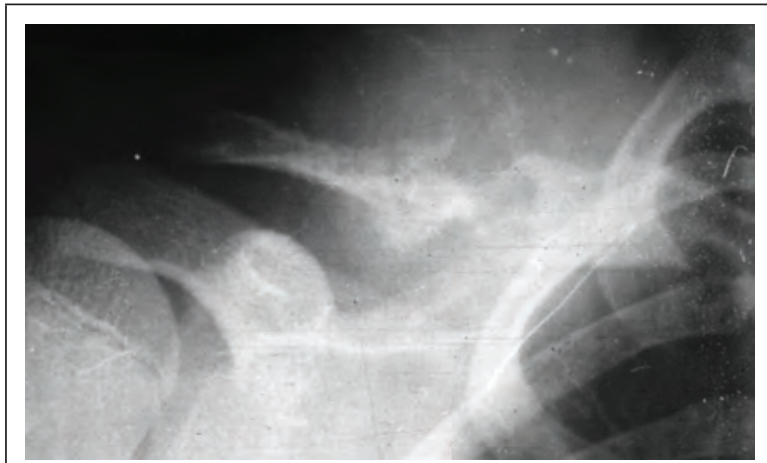

Figure 22c: Mixed type of periosteal reaction in histiocytic lymphoma of clavicle.

In metastatic malignancies [32] such as neuroblastoma and other malignancies, periosteal reaction is quite common with or without a pathological fracture [33] (Figure 23a,b).

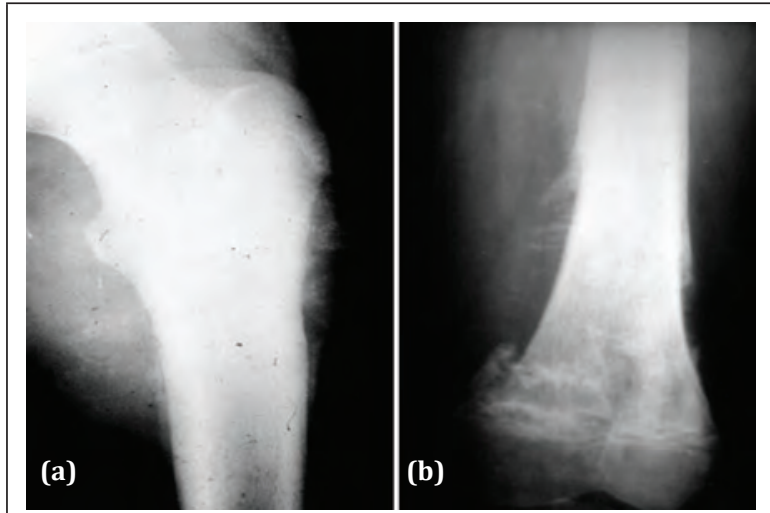

Figure 23a,b: Metastasis from neuroblastoma, (a) Upper end of femur, (b) Lower end of femur.

\section{Conclusion}

Periosteum is not visible radiographically unless it is mineralized. Ultrasonography is sensitive in detecting early periosteal reaction. The causative include ranging from traumatic to malignant lesions. The morphological types are many but any single type may not suggest the exact diagnosis. On the other hand, the type of periosteal reaction is specific to certain lesions. Periosteal reaction may be seen in primary lesions of the periosteum and lesions arising from structures other than periosteum. The types of periosteal reactions and the skeletal lesions that produce periosteal reaction are described illustratively.

\section{Acknowledgements}

NIMS, KIMS, KREST Museum Hyderabad.

\section{Conflicts of interest}

Author declares no conflicts of interest.

\section{References}

[1] Dwek JR. The periosteum: what is it, where is it, and what mimics it in its absence? Skeletal Radiol. 2010; 39(4):319323.

[2] Pradhan SK, Mutalik P, Swain A. Physiological periostitis: Reporting of a medical conundrum! West Afr J Radiol. 2013; 20(2):107-109.

[3] Forrester DM, Kirkpatrick J. Periostitis and pseudoperiostitis. Radiology, 1976; 118(3):597-601.

[4] Levine AH, Pais MJ, Berinson H, Amenta PS. The soleal line: A cause of tibial pseudoperiostitis. Radiology. 1976; 119(1):79-81.

[5] Rana RS, Wu JS, Eisenberg RL. Periosteal reaction. American Roentgen Ray Society - AJR. 2009; 193:W259-W272.

[6] Olvi LG, Santini-Araujo E. Periosteal desmoid. Tumors and Tumor-Like Lesions of Bone. 2015; Springer, London, pp. 731-765.

[7] Kiel J, Kaiser K - Stress reaction and fractures. Treasure Island (FL): StatPearls Publishing. Available from: https:// www.ncbi.nlm.nih.gov/books/NBK507835/

[8] Subbarao K. Shin splints. Radiological problem of the month. NY state J Med. 80:1419-1420.

[9] Barlas NB, Narkhede PN, Wilkinson M, Bilal A, Ashington UK et al. Periosteal reaction: A radiographic guide to disease process. Available from: https://dx.doi.org/10.1594/ ecr2013/C-1039

[10] Ando SM, Takahashi MS, Sakamoto FA, Rodrigues LBQ, NogueiraJunqueira JC, et al. Benign causes of periosteal reaction in paediatrics: part 1 . Available from: https:// dx.doi.org/10.1594/ecr2018/C-2601

[11] Ramirez I. Sickle cell anemia skeletal imaging. 2019. Available form: https://emedicine.medscape.com/article/413542overview

[12] Kirby K, Wright JE. Infantile cortical hyperostosis (Caffey Disease). StatPearls Publishing, Treasure Island (FL), 2018. Available form: https://europepmc.org/article/NBK/ NBK532878

[13] Dhawan R. Hypertrophic osteoarthropathy. Available from: https://emedicine.medscape.com/article/333735overview

[14] Yap FY, Skalski MR, Patel DB, Schein AJ, White EA, et al - Hypertrophic osteoarthropathy: Clinical and imaging features. Available from: https://doi.org/10.1148/ rg.2017160052

[15] Bell DJ,Ashraf A. Prostaglandin-induced cortical hyperostosis in infants with cyanotic congenital heart disease. Available form: https://radiopaedia.org/articles/prostaglandininduced-cortical-hyperostosis-in-infants-with-cyanoticcongenital-heart-disease-1

[16] Taybi H, Lachman RS. Radiology of syndromes, metabolic disorders, and skeletal dysplasias. (4th ed.) Chicago: Year Book, 1996.

[17] Scanlon GT, Clemett AR. Thyroid acropachy. Available from: https://doi.org/10.1148/83.6.1039

[18] Subbarao K. Musculoskeletal fluorosis - imaging spectrum. J Med Sci Res. 2013; 1(3):117-123. 
[19] Hacking C. Diffuse periosteal reaction due to chronic venous insufficiency. Available from: https://radiopaedia.org/ cases/diffuse-periosteal-reaction-due-to-chronic-venousinsufficiency

[20] Lichenstein L. Tumors of periosteal origin. Cancer 1955; 8:1060-1069.

[21] Brien EW, Mirra JM, Luck JV Jr. Benign and malignant cartilage tumors of bone and joint: their anatomic and theoretical basis with an emphasis on radiology, pathology and clinical biology. II. Juxtacortical cartilage tumors. Skeletal Radiol 1999; 28(1):1-20.

[22] Chai JW, Hong SH, Choi JY, Koh YH, Lee JW, et al. Radiologic diagnosis of osteoid osteoma: From simple to challenging findings. RadioGraphics. 2010; 30(3):737-749.

[23] Amar MF, Almoubaker S, Chbani B, Chahbouni S, Marzouki A, et al. Periosteal osteoid osteoma of the distal femur. Orthop Rev (Pavia). 2010; 2(2):e15.

[24] Deng F, Weerakkody Y. Osteoblastoma. Available from: https://radiopaedia.org/articles/osteoblastoma

[25] Lichenstein L, Halle JE. Periosteal chondroma: a distinctive benign cartilage tumor. J Bone Joint Surg Am 1952; 24(3):691-697.

[26] Jaffe HL. Juxtacortical chondroma. Bull Hosp Joint Dis 1956; 17(1):20-29

[27] Ando SM, Takahashi MS, Sakamoto FA, Rodrigues LBQ NogueiraJunqueira JC, et al. Malignant causes of periosteal reaction in paediatrics: part 2. Available from: https:// dx.doi.org/10.1594/ecr2018/C-2598

[28] Reid RP. Bone neoplasms and tumor-like lesions on the bone surface. In: Helliwell TR, ed. Pathology of bone and joint neoplasms. Philadelphia: Saunders, 1999; pp.215-235.

[29] Liu XW, Zi Y, Xiang LB, Han TY. Periosteal osteosarcoma: a review of clinical evidence. Int J Clin Exp Med. 2015; 8(1):37-44

[30] Lewis ML, Kenan S, Santiago MY, Norman A, Steiner G. Periosteal chondroma: a report of ten cases and a review of the literature. Clin Orthop. 1990; 256:185-192.

[31] Putti TC, Kahn LB, Aprin H. Periosteal chondrosarcoma: a case report and review of the literature. Arch Pathol Lab Med. 1997; 121(1):70-74.

[32] Vilar J, Lezana AH, Pedrosa CS. Spiculated periosteal reaction in metastatic lesions of bone. Skeletal Radiol. 1979; 3:230233.

[33] Subbarao K. Periosteal reaction in children. Indian J Pediatr. 1987; 54:45-52. 